\title{
Spatial variation of aerosol optical properties around the high-alpine site Jungfraujoch (3580 $\mathrm{m}$ a.s.l.)
}

\author{
P. Zieger ${ }^{1}$, E. Kienast-Sjögren ${ }^{2}$, M. Starace ${ }^{3}$, J. von Bismarck ${ }^{3}$, N. Bukowiecki ${ }^{1}$, U. Baltensperger ${ }^{1}$, F. G. Wienhold ${ }^{2}$, \\ T. Peter ${ }^{2}$, T. Ruhtz ${ }^{3}$, M. Collaud Coen ${ }^{4}$, L. Vuilleumier ${ }^{4}$, O. Maier ${ }^{4}$, E. Emili $^{5}{ }^{*}$, C. Popp ${ }^{6}$, and E. Weingartner ${ }^{1}$ \\ ${ }^{1}$ Paul Scherrer Institute, Laboratory of Atmospheric Chemistry, 5232 Villigen, Switzerland \\ ${ }^{2}$ Institute for Atmospheric and Climate Science, ETH Zurich, 8092, Zurich, Switzerland \\ ${ }^{3}$ Institute for Space Sciences, Freie Universität Berlin, 12165 Berlin, Germany \\ ${ }^{4}$ Federal Office of Meteorology and Climatology, 1530 Payerne, Switzerland \\ ${ }^{5}$ Department of Geography, University of Bern, 3012 Bern, Switzerland \\ ${ }^{6}$ Empa, Swiss Federal Laboratories for Materials Science and Technology, 8600 Dübendorf, Switzerland \\ *now at: CERFACS, 31057 Toulouse, France
}

Correspondence to: P. Zieger (paul.zieger@alumni.ethz.ch)

Received: 8 March 2012 - Published in Atmos. Chem. Phys. Discuss.: 2 May 2012

Revised: 10 July 2012 - Accepted: 31 July 2012 - Published: 8 August 2012

\begin{abstract}
This paper presents results of the extensive field campaign CLACE 2010 (Cloud and Aerosol Characterization Experiment) performed in summer 2010 at the Jungfraujoch (JFJ) and the Kleine Scheidegg (KLS) in the Swiss Alps. The main goal of this campaign was to investigate the vertical variability of aerosol optical properties around the JFJ and to show the consistency of the different employed measurement techniques considering explicitly the effects of relative humidity $(\mathrm{RH})$ on the aerosol light scattering. Various aerosol optical and microphysical parameters were recorded using in-situ and remote sensing techniques. In-situ measurements of aerosol size distribution, light scattering, light absorption and scattering enhancement due to water uptake were performed at the JFJ at $3580 \mathrm{~m}$ a.s.1.. A unique set-up allowed remote sensing measurements of aerosol columnar and vertical properties from the KLS located about $1500 \mathrm{~m}$ below and within the line of sight to the JFJ (horizontal distance of approx. $4.5 \mathrm{~km}$ ). In addition, two satellite retrievals from the Spinning Enhanced Visible and Infrared Imager (SEVIRI) and the Moderate Resolution Imaging Spectroradiometer (MODIS) as well as back trajectory analyses were added to the comparison to account for a wider geographical context. All in-situ and remote sensing measurements were in clear correspondence. The ambient extinction coefficient measured in situ at the JFJ agreed well with the KLSbased LIDAR (Light Detection and Ranging) retrieval at the
\end{abstract}

altitude-level of the JFJ under plausible assumptions on the LIDAR ratio. However, we can show that the quality of this comparison is affected by orographic effects due to the exposed location of the JFJ on a saddle between two mountains and next to a large glacier. The local RH around the JFJ was often higher than in the optical path of the LIDAR measurement, especially when the wind originated from the south via the glacier, leading to orographic clouds which remained lower than the LIDAR beam. Furthermore, the dominance of long-range transported Saharan dust was observed in all measurements for several days, however only for a shorter time period in the in-situ measurements due to the vertical structure of the dust plume. The optical properties of the aerosol column retrieved from SEVIRI and MODIS showed the same magnitude and a similar temporal evolution as the measurements at the KLS and the JFJ. Remaining differences are attributed to the complex terrain and simplifications in the aerosol retrieval scheme in general.

\section{Introduction}

Atmospheric aerosols impact the Earth's climate by scattering and absorbing incoming solar radiation and thus influence the Earth's global energy budget (Trenberth et al., 2009). Precise measurements of aerosol properties are 


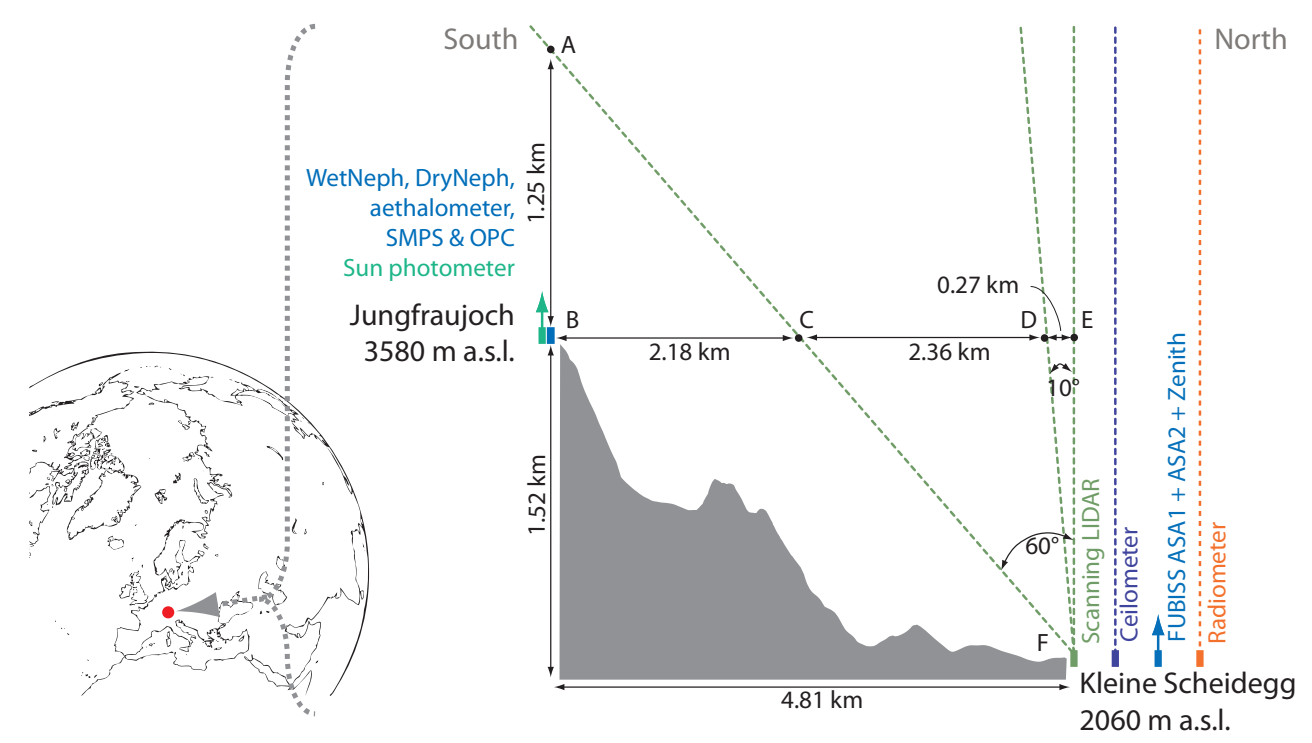

Fig. 1. Set-up and measurement geometry during the CLACE 2010 campaign performed at the Jungfraujoch and the Kleine Scheidegg, Switzerland (red bullet on left map).

essential to develop and evaluate aerosol optical, microphysical and transport models, which are required to improve our understanding on the impact of aerosols on climate (Ghan and Schwartz, 2007). However, a thorough quantification of the direct and indirect aerosol effects on the Earth's radiative budget is difficult to achieve, due to the high spatial and temporal variability along with large differences in aerosol composition and size. Currently, a large variety of different in-situ and remote sensing techniques exist which observe aerosols from the ground, from moving platforms like airplanes or from satellites (see e.g. Chin et al., 2009; Schmid et al., 2006; Kaufman et al., 2002, and references therein).

Closure studies have been proposed (see e.g. Ogren, 1995; Penner et al., 1994) and initiated to assess the consistency of aerosol properties measured with various techniques from different platforms. For example, closure studies between LIDAR (Light Detection And Ranging) and in situ measured aerosol size distribution, scattering and absorption coefficients (often together with Mie theory) have been performed in several studies (see e.g. Hoffmann et al., 2012; Zieger et al., 2011; Fierz-Schmidhauser et al., 2010b; Schmid et al., 2003; Gobbi et al., 2003; Fiebig et al., 2002; Wex et al., 2002; Russell and Heintzenberg, 2000; Hoff et al., 1996, and references therein). An overview on closure studies with a focus on mineral dust is given in a recent publication by Ansmann et al. (2011). Since aerosol particles experience hygroscopic growth at elevated relative humidity $(\mathrm{RH})$, the comparison of the usually dry in-situ measurements ( $\mathrm{RH}<30-40 \%$ as recommended by WMO/GAW, 2003) with the ambient remote sensing measurements is complicated. However, a few studies have used direct measurements of the hygroscopicity to compare their in-situ measurements with ambient ones (see e.g. Zieger et al., 2011; Pahlow et al., 2006). Concerning the type of closure study, one often differentiates between a column and local closure (Russell and Heintzenberg, 2000). In a local closure, measurements at a distinct place (e.g. from a common sampling line) are being compared and tested against model calculations. In a column closure, vertical profiles of aerosol properties are compared to integrated values retrieved e.g. from satellite retrievals or ground-based columnar measurements.

This study presents the results of a combined optical closure study - local and columnar - performed in summer 2010 in the Swiss Alps. In an exceptional set-up various remote sensing instruments were installed at the Kleine Scheidegg (2060 $\mathrm{m}$ a.s.1., $\left.46^{\circ} 35^{\prime} 6^{\prime \prime} \mathrm{N}, 7^{\circ} 57^{\prime} 40^{\prime \prime} \mathrm{E}\right)$ and different in-situ instruments were recording at the Jungfraujoch ( $3580 \mathrm{~m}$ a.s.1., $\left.46^{\circ} 32^{\prime} 51^{\prime \prime} \mathrm{N}, 7^{\circ} 58^{\prime} 45^{\prime \prime} \mathrm{E}\right)$ approximately $1.5 \mathrm{~km}$ above and in the line of sight of the remote sensing site (approx. $4.5 \mathrm{~km}$ horizontal distance, see Fig. 1). This set-up allows to investigate the vertical distribution of the aerosols in combination with a detailed microphysical and optical analysis at one point in the column at a high temporal resolution. In addition, data from two satellites, which account for a wider geographical context than the solely ground-based instrumentation, are added to the comparison.

An extensive local closure experiment concerning aerosol optical properties was already conducted at the Jungfraujoch (Fierz-Schmidhauser et al., 2010b). In that study, hygroscopic measurements of a humidified nephelometer and a Hygroscopicity Tandem Differential Mobility Analyzer (HTDMA) together with size distribution, light scattering, light absorption and chemical measurements were discussed and compared using Mie theory. Local closure was achieved in Fierz-Schmidhauser et al. (2010b), but the comparison to ambient data was still missing and is now done in this study. The 
presented work is also motivated by the results of a recent field study at Cabauw, the Netherlands, where in-situ measurements of the ambient aerosol extinction coefficient were compared to MAX-DOAS (Multi-Axis Differential Optical Absorption Spectroscopy) and LIDAR (Zieger et al., 2011). Significant differences between MAX-DOAS, LIDAR and (ambient) in-situ measurements were found for the lowest level in Cabauw. In Zieger et al. (2011), the LIDAR profiles had to be extrapolated to retrieve the ground layer value due to the incomplete overlap of transmitter and receiver, which is now being avoided by the elevated position of the in-situ measurements. In this study, a local closure between in-situ and LIDAR profiles and a column closure between the integrated LIDAR profiles, the Sun photometers and two different satellite retrievals is presented.

\section{Experimental setup}

\subsection{Site and campaign description}

The Cloud and Aerosol Characterization Experiment (CLACE) 2010 campaign took place from June to August 2010 at the high alpine research station Jungfraujoch ( $3580 \mathrm{~m}$ a.s.l., $\left.46^{\circ} 32^{\prime} 51^{\prime \prime} \mathrm{N}, 7^{\circ} 58^{\prime} 45^{\prime \prime} \mathrm{E}\right)$ and the Kleine Scheidegg ( $2060 \mathrm{~m}$ a.s.1., $46^{\circ} 35^{\prime} 6^{\prime \prime} \mathrm{N}, 7^{\circ} 57^{\prime} 40^{\prime \prime} \mathrm{E}$ ), Switzerland. The Kleine Scheidegg (KLS) is located approx. $1.5 \mathrm{~km}$ below the Jungfraujoch (JFJ) and both sites are in direct range of sight (horizontal distance approx. $4.5 \mathrm{~km}$, see Fig. 1). The JFJ research station is part of the Global Atmosphere Watch (GAW) program coordinated by the World Meteorological Organization (WMO) and continuous aerosol insitu measurements have been performed within this framework since 1995. The continuous Precision Filter Radiometers (PFR) measurements by MeteoSwiss date back to 1999 . However, there were measurements with other types of Sun photometers since 1995 (less continuous).

Due to its high altitude the JFJ site is situated in the free troposphere for most of the time. Thermal convection, however, transports air from the planetary boundary layer (PBL) to the site, especially during the warmer summer months and predominantly in the afternoon hours. Therefore, the extensive aerosol parameters, e.g. aerosol scattering coefficient or number concentration, undergo an annual cycle with a maximum in the summer months and a minimum during winter months. This goes along with a typical diurnal cycle showing a maximum in aerosol concentration in the afternoon hours (see e.g. Collaud Coen et al., 2011, 2007; Nyeki et al., 1998; Baltensperger et al., 1997). The site is also exposed to long-range transport phenomena, such as Saharan dust from Northern Africa (Collaud Coen et al., 2004; Schwikowski et al., 1995) or volcanic ash from Iceland (Bukowiecki et al., 2011). In contrast to the permanent facilities at the JFJ, the KLS site was a temporary measurement site especially in- stalled for the CLACE 2010 campaign, where only remote sensing instruments were located.

The CLACE campaigns have been carried out on a regular basis since 2000 at the Jungfraujoch (see http://www.psi. $\mathrm{ch} / \mathrm{lac} / \mathrm{clace}$-gaw-plus for an overview). Their main goal is to study the microphysical properties of aerosols and clouds using a wide range of in-situ and remote sensing techniques. During CLACE 2010, the focus was set on investigating the ambient peak supersaturation and size distribution of liquid clouds (Spiegel et al., 2012; Hammer et al., 2012), the influence of the planetary boundary layer at the JFJ (Ketterer et al., 2012), and the closure study of aerosol optical properties using in-situ and remote sensing techniques (this study).

An intensive operation period (IOP) was defined for a two-week interval (3-18 July 2010), where all instruments were successfully operated in parallel. During this time also columnar aerosol optical properties were measured from the KLS with the FUBISS instrumentation (Free University Berlin Integrated Spectrographic System, see Sect. 2.3.2). This period was also characterized by many cloud-free days, which are needed for the remote sensing of aerosols. This study therefore focuses on the two-week long IOP.

\subsection{In-situ instrumentation at the Jungfraujoch}

All aerosol instruments were connected to a heated inlet $\left(\approx 25^{\circ} \mathrm{C}\right.$, without size cut), which besides aerosol particles also allows hydrometeors with diameter $D<40 \mu \mathrm{m}$ to enter and to evaporate, at wind speeds up to $20 \mathrm{~ms}^{-1}$ (Weingartner et al., 1999). This allows that cloud residuals are included in the aerosol measurements. The temperature difference between ambient and inside the laboratory additionally guarantees that all aerosol measurements are performed at dry conditions (relative humidity, $\mathrm{RH}<20 \%$ ).

\subsubsection{Aerosol scattering coefficient measurements at dry and humidified conditions}

The measurement of scattering and backscattering coefficients has continuously been performed at the JFJ since 1995 . An integrating nephelometer (TSI Inc., Model 3563, subsequently termed DryNeph) measures the aerosol light scattering $\sigma_{\mathrm{sp}}$ and backscattering $\sigma_{\mathrm{bsp}}$ coefficient at three wavelengths $(\lambda=450,550$, and $700 \mathrm{~nm})$. The scattering coefficients were measured at dry conditions $\left(\mathrm{RH}_{\mathrm{dry}}=14.5 \pm\right.$ $4.3 \%$ (mean \pm standard deviation) inside the nephelometer during the IOP).

In addition, the aerosol scattering coefficients $\sigma_{\mathrm{sp}}$ were measured with a novel humidified nephelometer (WetNeph) at defined relative humidity between $\sim 20-95 \%$ RH. A detailed technical description of the WetNeph is given by FierzSchmidhauser et al. (2010a). Briefly, the instrument consists of a modified TSI nephelometer (TSI Inc., Model 3563 with an improved temperature and RH control) coupled to a humidification and drying system. The main feature of this 
instrument is the measurement of humidograms, where the $\mathrm{RH}$ inside the nephelometer is periodically changed from approximately 20 to $95 \%$. In the hydration mode of the humidogram, the RH is increased from low to high RH while the dryer is turned off. In this mode, the lower part of the aerosol hysteresis curve is measured. In the dehydration mode, the humidifier is set to maximum $\mathrm{RH}(\approx 95 \%)$ and the following dryer is now turned on, drying the aerosol back to dry conditions to approx. 20-35\% RH. This mode allows the sampling of the upper branch of the hysteresis curve. Typical humidograms measured at the JFJ are shown by Fierz-Schmidhauser et al. (2010b).

The measurement of the dry and wet scattering coefficients by the DryNeph and the WetNeph allows the determination of the scattering enhancement factor $f(\mathrm{RH})$, which is defined as:

$f(\mathrm{RH}, \lambda)=\frac{\sigma_{\mathrm{sp}}(\mathrm{RH}, \lambda)}{\sigma_{\mathrm{sp}}\left(\mathrm{RH}_{\mathrm{dry}}, \lambda\right)}$,

where $\sigma_{\mathrm{sp}}$ is the aerosol scattering coefficient at a certain RH and wavelength $\lambda$. All optical properties discussed here are dependent on the wavelength $\lambda$, which is omitted for simplicity reasons from now on and only explicitly mentioned when misinterpretation could occur. The numerator of Eq. (1) is measured by the WetNeph while the denominator is measured by the DryNeph $\left(\mathrm{RH}_{\text {dry }}\right.$ is the relative humidity inside the DryNeph). The scattering coefficient were corrected for angular and illumination non-idealities (truncation error correction, see Anderson and Ogren, 1998). During the CLACE 2010 campaign, the WetNeph was operated in the humidogram mode and a full scan from low to high $\mathrm{RH}$ and back took three hours. The shape and magnitude of the recorded humidograms are similar to the findings of Fierz-Schmidhauser et al. (2010b) who measured the scattering enhancement in May 2008 at the JFJ using the same instrument as in this study.

\subsubsection{Aerosol absorption measurements}

An aethalometer (Magee Scientific, USA, type AE31) was used to measure the aerosol light absorption coefficients $\sigma_{\mathrm{ap}}$ at the wavelengths of $\lambda=370,470,520,590,660,880$, and $950 \mathrm{~nm}$. The principle of the aethalometer is to measure the attenuation of light transmitted through a filter (Pallflex Q250F), while aerosols are continuously deposited on the filter, which is changed after a certain threshold of the attenuation has been reached. The measurements were corrected for multiple scattering by the filter fibers and the scattering of the aerosols embedded in the filter using a site-specific correction factor of 2.81 (Collaud Coen et al., 2010). A loading dependent correction was not applied. For further information on the correction algorithms see Weingartner et al. (2003) and Collaud Coen et al. (2010).

The sum of $\sigma_{\mathrm{ap}}$ and $\sigma_{\mathrm{sp}}$, as measured by the aethalometer and nephelometer, is called the aerosol extinction coefficient $\sigma_{\mathrm{ep}}$. The ratio of the scattering coefficient $\sigma_{\mathrm{sp}}$ to the extinction coefficient $\sigma_{\text {ep }}$ is called the single scattering albedo $\omega_{0}$ :

$\omega_{0}=\frac{\sigma_{\mathrm{sp}}}{\sigma_{\mathrm{sp}}+\sigma_{\mathrm{ap}}}=\frac{\sigma_{\mathrm{sp}}}{\sigma_{\mathrm{ep}}}$.

The single scattering albedo can vary from $\omega_{0}=1$ (extinction entirely caused by scattering) to $\omega_{0}=0$ (extinction entirely caused by absorption).

\subsubsection{Aerosol size distribution measurements}

Dry aerosol number size distributions were measured for mobility diameters $\left(D_{\mathrm{mob}}\right)$ between 10 and $350 \mathrm{~nm}$ with a Scanning Mobility Particle Sizer (SMPS). It consists of a Differential Mobility Analyzer (DMA, TSI Inc., Model 3071) and a Condensation Particle Counter (CPC, TSI Inc., Model 3775). Size distributions were measured every $6 \mathrm{~min}$, with an up-scan time of $300 \mathrm{~s}$. The DMA was operated at $0.31 \mathrm{~min}^{-1}$ sample air flow rate and a closed-loop excess and sheath air setup with a flow rate of $31 \mathrm{~min}^{-1}$. The used SMPS type was previously intercompared within the EUSAAR project (http: //www.eusaar.net) and fulfills the recommendations given by Wiedensohler et al. (2012).

Additional size distribution measurements were performed by a 15-channel Optical Particle Counter (OPC; Dust Monitor 1.108, Grimm GmbH). The instrument was factory calibrated using polystyrene latex spheres (PSLs, refractive index $=1.588)$ at a laser wavelength of $780 \mathrm{~nm}$, yielding optical diameter $\left(D_{\text {opt }}\right)$ size ranges of $>0.3 \mu \mathrm{m}$ to $>20 \mu \mathrm{m}$ in 15 different channels. The nominal volumetric flow rate of $1.21 \mathrm{~min}^{-1}$ was increased to $1.41 \mathrm{~min}^{-1}$ due to the pressure conditions at the JFJ (640-670 mbar). The flow was checked at regular intervals (every 3-7 days during the campaign), and the measured number concentrations were corrected for the increased flow rate. Based on the length and geometric design of the OPC inlet line, it was estimated that there is a considerable loss of particles with $D>15 \mu \mathrm{m}$. Aerosol measurements with an OPC depend on the shape and the complex refractive index of the sampled aerosol, which determine the scattering response function and thus cause a large uncertainty in the correct sizing of the particles. The recorded OPC size distributions were corrected assuming a constant refractive index $m_{\mathrm{OPC}}$ as described in Bukowiecki et al. (2011).

\subsubsection{Meteorological data}

All meteorological parameters, (temperature $T$, relative humidity $\mathrm{RH}$, wind speed and direction) were measured at the JFJ SwissMetNet station operated by MeteoSwiss. A THYGAN (Thermo-HYGrometer-ANetz), measured the air temperature with a thermocouple and the relative humidity was measured by a chilled dew point mirror hygrometer. The measurement uncertainty of the temperature and the dew point was of $\pm 0.15^{\circ} \mathrm{C}$ for $T>-20^{\circ} \mathrm{C}$ and $\pm 0.25^{\circ} \mathrm{C}$ for $T<-20^{\circ} \mathrm{C}$. 


\subsection{Remote sensing instrumentation}

\subsubsection{Aerosol backscatter LIDAR}

The Institute for Atmospheric and Climate Science of ETH Zurich installed a scanning elastic backscatter LIDAR (Light Detection And Ranging) at the KLS. This instrument (Model ALS450, Leosphere, Orsay, France) emits a laser pulse $(\lambda=355 \mathrm{~nm}$, average pulse energy $16 \mathrm{~mJ}$, repetition rate $20 \mathrm{~Hz}, 1.5 \mathrm{~m}$ vertical resolution) and records the attenuated backscatter signal that is elastically scattered back from air molecules, aerosols and cloud droplets. The LIDAR equation describes the detected signal $P$ resulting from scattering by air molecules and particles at distance $R$ from the instrument as (see e.g. Weitkamp, 2005, for more details):

$$
P(R) R^{2}=E_{0} v_{L}\left[\beta(R)+\beta_{\mathrm{m}}(R)\right] \cdot \exp \left[-2 \int_{r_{0}}^{R}\left[\sigma_{\mathrm{ep}}(r)+\sigma_{\mathrm{m}}(r)\right] \mathrm{d} r\right],
$$

where $E_{0}$ denotes the laser pulse energy, and $v_{L}$ is an instrument specific efficiency parameter (the overlap function is included in $v_{L}$ ), $\beta$ and $\sigma$ describe the backscatter and extinction by air molecules ("m" for molecular) and aerosol particles ("ep" for extinction by particles as commonly used for in-situ measurements). The product of $P(R) R^{2}$ is called range corrected backscatter signal (RCS). The molecular coefficients in Eq. (3) are evaluated from atmospheric temperature and pressure profiles taken from the operational weather forecast model COSMO re-analysis data with a horizontal resolution of $2 \mathrm{~km}$ (see http://www.cosmo-model.org).

The aerosol backscatter and extinction coefficients $\beta$ and $\sigma_{\text {ep }}$ in Eq. (3) remain two unknowns for one recorded measurement quantity. The ratio of both parameters is usually defined as the aerosol LIDAR ratio LR:

$\operatorname{LR}(R)=\frac{\sigma_{\mathrm{ep}}(R)}{\beta(R)}$.

It depends on the particle size, shape and chemical composition. Similarly, the molecular LIDAR ratio $\mathrm{LR}_{\mathrm{m}}$ is defined as

$\mathrm{LR}_{\mathrm{m}}=\frac{\sigma_{\mathrm{m}}}{\beta_{\mathrm{m}}}=\frac{8 \pi}{3} F_{\mathrm{k}}$,

where $F_{\mathrm{k}} \sim 1$ is the King correction factor, which takes the anisotropy of air molecules into account and can be calculated (She, 2001; Bucholtz, 1995). Since the aerosol LIDAR ratio cannot be determined independently with elastic backscatter LIDAR systems, it has to be prescribed as parameter for the inversion of Eq. (3). Using the Klett algorithm (Kovalev and Eichinger, 2004), profiles of the aerosol extinction coefficient $\sigma_{\mathrm{ep}}$ are determined.

The LIDAR is equipped with a parallel and a perpendicular receiver channel, $P_{\|}$and $P_{\perp}$, which allow determining the degree of depolarization of the initially linearly polarized laser pulse. The linear volume depolarization ratio $\delta$ is defined as

$\delta=\frac{P_{\perp}}{P_{\|}}$,

where the signal ratio is evaluated using the manufacturer supplied instrumental calibration factor.

The LIDAR was tilted at a zenith angle of $10^{\circ}$ towards the JFJ for most of the time of the campaign and from 8 to 17 July 2010 with a closer angle of $60^{\circ}$ towards the JFJ (see Fig. 1). The profile heights were therefore corrected by the cosine of the zenith angle to produce vertical altitude. A moving average in time $( \pm 22.5 \mathrm{~min})$ and altitude $( \pm 225 \mathrm{~m})$ was applied to all LIDAR profiles.

\subsubsection{FUBISS-ASA1 + ASA2 measurements}

The multi-spectral Sun and aureole-radiometers FUBISSASA1 and FUBISS-ASA2 (Free University Berlin Integrated Spectrographic System - Aureole and Sun Adapter 1 and 2) are designed for aerosol remote sensing on moving as well as on ground based platforms (both instruments and calibration procedures are described in detail in Zieger et al., 2007; Asseng et al., 2004). They are frequently used for airborne measurements of aerosol optical properties. Both instruments were deployed at the KLS during the IOP only.

ASA2 is the newer system and includes two aureole baffle tubes in addition to the Sun photometer optics. These aureole tubes consist of various ring shaped apertures which shield the direct sunlight and only allow radiation from the $4^{\circ}$ and $6^{\circ}$ angle regions to be transmitted to the spectrometers (the exact angles of these annulus rings around the Sun are $3.05^{\circ}-4.82^{\circ}$ and $4.68^{\circ}-7.24^{\circ}$ ). The spectrometers provide 256 wavelengths channels between $\lambda=300$ and $1100 \mathrm{~nm}$. Radiometric calibration of the Sun photometer is performed by the Langley-plot technique together with a method using the measured aureole radiances as suggested by Tanaka et al. (1986). The required calibration coefficient for the selected spectrometer pixels is the extraterrestrial detector voltage $V_{0}$, extrapolated from continuous measurements in the hours after sunrise or before sunset, when the direct solar radiance traverses a range of different air masses. To meet the requirements of stable atmospheric conditions during the calibration measurements, they are favorably performed above the planetary boundary layer. FUBISS-ASA1 and ASA2 were calibrated before and after IOP at the JFJ. Under clear sky and stable atmospheric conditions, the Langley-plot technique has an accuracy better than $1 \%$ of the extraterrestrial detector voltage (Schmid and Wehrli, 1995; Asseng et al., 2004, see Eq. 7 below). The relative differences of the sensitivity of the solar and the aureole radiometers had previously been determined by measurements with a standard lamp in an integrating sphere.

Scattering and absorption by air molecules, cloud droplets, and aerosols lead to the extinction of solar radiation entering 
the atmosphere. Under cloud-free conditions the integrated extinction from the instrument to the top of the atmosphere due to aerosol particles, the aerosol optical depth $\tau_{a}$ (AOD), can be derived from the measured direct solar signal $V_{\mathrm{d}}$ using the rearranged Beer-Lambert law

$\tau_{a}=\frac{\ln \left(V_{0}\right)-\ln \left(V_{\mathrm{d}}\right)}{m}-\tau_{\mathrm{r}}-\tau_{\mathrm{g}}$,

where $V_{0}$ is the extraterrestrial detector voltage. The relative air mass factor $m$ in Eq. (7) normalizes the optical depth to the zenith direction. $\tau_{\mathrm{r}}$ refers to the optical thickness due to Rayleigh scattering by air molecules, which is calculated. With a priori assumptions for the spectral behavior of AOD, the optical thickness of absorbing trace gases $\tau_{\mathrm{g}}$ can be derived from the Sun photometer measurements by minimizing the residual to synthetic results computed under variation of the assumed trace gas concentration (King and Byrne, 1978). In the processing scheme used for the CLACE campaign this method was adopted for the correction of the ozone contribution to the optical depth. The spectral shape of the AOD contains information about the size distribution of the aerosol particles. The parameter used to quantify the latter is called Ångström exponent, $\alpha$, and can be derived from the fit of a power law, called the Ångström formula, to the spectral slope of the AOD:

$\tau_{a}(\lambda) \sim \lambda^{-\alpha}$.

Relation (8) can be formulated analogously for $\sigma_{\mathrm{sp}}, \sigma_{\mathrm{ap}}, \sigma_{\mathrm{ep}}$, or the single scattering albedo $\omega_{0}$ (see Eq. 2). The exponent can be determined by fitting a power law function to the measured spectral aerosol optical depth or by using two discrete wavelengths $\lambda_{1}$ and $\lambda_{2}$. For small exponents $(\alpha \lesssim 1)$ the measured aerosol is dominated by the coarse mode $(D>1 \mu \mathrm{m})$, whereas for large values $(\alpha \gtrsim 1)$ the size distributions is dominated by the fine mode $(D<1 \mu \mathrm{m})$.

As mentioned above, FUBISS-ASA2 detects the scattered radiation in the two annulus rings at $4^{\circ}$ and $6^{\circ}$. This allows to retrieve the ratio of the aerosol phase function $P_{\mathrm{a}}$ (averaged over each aureole ring at the two angles), which is defined as the aureole index aui:

$\operatorname{aui}(\lambda):=\frac{P_{\mathrm{a}, 4^{\circ}}}{P_{\mathrm{a}, 6^{\circ}}}$.

This spectrally dependent value can be interpreted as the slope or steepness of the aerosol phase function in the forward scattering region. It allows to estimate the observed aerosol type, if e.g. compared to values computed by Mie calculations for different aerosol types like sea salt, desert dust or urban aerosol (see Zieger et al., 2007). The spectral dependence of the aui value can additionally be used for the analysis. A further advantage of the additional aureole measurements lies in an easy detection of thin (and for the human eye invisible) clouds that immediately cause an increased aureole signal due to the increased forward scattering.

\subsubsection{Ceilometer}

A Jenoptic LIDAR-ceilometer CHM 15k (http://www. jenoptik.com) was installed at the KLS. The CHM 15k is a low-maintenance low-power elastic backscatter LIDAR. It uses a diode-pumped $\mathrm{Nd}$ : YAG solid state laser at $\lambda=$ $1064 \mathrm{~nm}$ with a repetition frequency of $5-7 \mathrm{kHz}$ and a pulse duration of $1 \mathrm{~ns}$. It provides vertical profiles of total (molecular + particulate) elastic backscatter from about $300 \mathrm{~m}$ above ground up to $15 \mathrm{~km}$ (under cloud-free conditions) with a vertical resolution of $15 \mathrm{~m}$. We only use the range corrected signal for illustration purposes.

\subsubsection{Radiometer}

A microwave profiler (TEMPRO, Radiometer Physics $\mathrm{GmbH}$, Germany) was installed at the KLS to retrieve temperature profiles. TEMPRO is a total-power radiometer utilizing direct detection receivers in the V-band with seven channels from 51 to $58 \mathrm{GHz}$. These channels contain information on the vertical temperature profile due to the homogeneous mixing of $\mathrm{O}_{2}$ in the atmosphere (Crewell and Löhnert, 2007). A full description of the instrument and of the retrieval algorithm is given in Löhnert and Maier (2012). The a priori information needed for a reliable retrieval of the temperature profiles is usually taken from radiosonde measurements. Unfortunately, direct soundings at the KLS were not available and therefore soundings from Payerne, Switzerland, were used instead (located approx. $80 \mathrm{~km}$ west of the JFJ). The retrieved profiles therefore have to be used with caution. They are only used here to show relative differences between the temperature measurement at the $\mathrm{JFJ}$ and the temperature profile value at the height of the JFJ station (Point E in Fig. 1).

\subsubsection{MeteoSwiss Sun photometers at the JFJ}

AOD measurements are performed at the Jungfraujoch using Precision Filter Radiometers (PFR, see Wehrli, 2000). PFR's are designed for long-term monitoring and feature some characteristics for reducing instrumental drift, for example temperature stabilization or a shutter to reduce filter and sensor degradation. These measurements are performed within the SACRaM network (Swiss Alpine Climate Radiation Monitoring of MeteoSwiss), which operates four 4-wavelength PFR units at the Jungfraujoch. Nine out of these 16 wavelengths allow inferring AOD between 368 and $1024 \mathrm{~nm}$. AOD values (see Eq. 7) are derived from atmospheric transmittances that are measured every minute. The SACRaM PFR's are calibrated using the Langley plot technique, which are conducted on exceptionally stable days (about 1 in 10 on average at the Jungfraujoch). This calibration procedure at the Jungfraujoch allows reducing the uncertainty on the estimate of the extraterrestrial signal to about $1 \%$. The estimate of the extraterrestrial signal is used 
as a normalization, and a $1 \%$ uncertainty corresponds to an uncertainty of 0.005 in the AOD (Schmid and Wehrli, 1995).

\subsection{Satellite observations}

Spaceborne aerosol products provide a large-scale and synoptic view of the atmospheric aerosol abundance and distribution. In this study, operationally derived AOD (at $\lambda=$ $550 \mathrm{~nm}$ ) from the Spinning Enhanced Visible and Infrared Imager (SEVIRI) on-board the current European geostationary METEOSAT Second Generation (MSG) satellites and from the polar-orbiting Moderate Resolution Imaging Spectroradiometer (MODIS) are used to put the ground-based measurements into a wider context. The main challenge of satellite aerosol retrieval lies in the separation of the aerosol signal from the surface reflectance signal, which is a priori unknown. The SEVIRI AOD product (Popp et al., 2007) is based on time-series analyses of the SEVIRI visible band to first estimate surface reflectance for each pixel and timeslot and to subsequently invert AOD by means of radiative transfer calculations assuming a fixed (continental) aerosol model. SEVIRI AOD maps over Central Europe are generated with a temporal resolution of 15 min for all clear-sky pixels during daytime (solar zenith angle $<75^{\circ}$ ) and a resolution after spatial filtering of approximately $20 \mathrm{~km}$. Validation of SEVIRI derived AOD with AErosol RObotic NETwork (AERONET, Holben et al., 1998) sites in Central Europe revealed a generally good performance (correlations well above 0.8 , root-mean-square error (RMSE) of $\sim 0.05$, and $75-80 \%$ of all retrievals within MODIS expected error over land of $\pm(0.05+0.15 \times$ AOD $)$, Popp et al., 2009). A validation of SEVIRI AOD carried out specifically over some Alpine sites and the relative discussion can also be found in Emili et al. (2010). In the MODIS Collection 5 (Levy et al., 2007) overland aerosol retrievals, the infrared bands (1.24, $2.1 \mu \mathrm{m}$ ), which are less sensitive to the aerosol signal, are used to estimate the surface reflectance in the visible bands for each observation (Kaufman et al., 1997). In order to reduce noise (e.g. due to undetected clouds/snow and bright spots) the 20 to 50 percentile of surface reflectance is averaged in squares of $10 \times 10 \mathrm{~km}^{2}$ prior to the AOD inversion. The accuracy of the MODIS AOD over land was found to be $\Delta \mathrm{AOD}= \pm(0.05+0.15 \times \mathrm{AOD})$ worldwide $(68 \%$ confidence level, Levy et al., 2010). The availability of two visible bands allows to estimate the aerosol fine and coarse modes, or alternatively the Ångström exponent. However, the latter is considered more as a qualitative product over land (Levy et al., 2010). For this study, daily MODIS products (Collection 5.1 Level 3; MOD08D3, MYD08D3) were downloaded from the NASA Giovanni Web site (http://disc.sci.gsfc.nasa. gov/giovanni/overview/index.html). Among the major error sources of both aerosol products are inappropriate surface reflectance estimation and undetected cloud and snow contamination which makes remote sensing of aerosol properties in mountainous regions particularly challenging (Emili et al., 2011).

\section{Results}

First, a short overview on the prevailing air masses and their aerosol related properties are presented in Sect. 3.1. Next, in Sect. 3.2, we discuss the calculation of optical properties. This is followed by a comparison study of the extinction coefficients measured in situ and by LIDAR in Sect. 3.3. The influence of a strong Saharan dust plume transported to the site was observed during the IOP by all instruments, which is discussed in Sect. 3.4. A discussion on the columnar measurements of FUBISS, the Sun photometer at the JFJ and the satellite observations follows in Sect. 3.5.

\subsection{Prevailing air masses and their aerosol properties}

The intensive observation period (IOP) was characterized by many cloud-free days, which are a prerequisite for the remote sensing of aerosols. Especially the AOD measurements are only feasible during clear sky conditions, which were possible at eight days (mainly during the morning) out of the 14 day long IOP.

The air during the IOP mainly originated from Western Europe as can be seen in Fig. 2, where air mass trajectories are shown (5-day backward calculations with a time resolution of six hours using the FLEXTRA model (Stohl et al., 1995; Stohl and Seibert, 1998), trajectories taken from NILU at http://www.nilu.no/trajectories). The trajectories are color coded by different aerosol parameters measured at the time the air parcel arrived at the site. The first three panels in Fig. 2 present the main intensive aerosol optical parameters. The Ångström exponent $\alpha_{\text {dry, scat }}$ (see Eq. 8) of the dry scattering coefficient measured in situ at the JFJ by the nephelometer is seen in Fig. 2a. Large values $\left(\alpha_{\text {dry, scat }} \gtrsim 1\right)$ point towards a dominant fine mode, while small values $\left(\alpha_{\text {dry, scat }} \lesssim 1\right)$ indicate a coarse mode domination of the aerosol size distribution. It can be seen that a value of $\alpha_{\mathrm{dry} \text {, scat }} \approx 2$ prevails for most of the time which can be regarded as the typical background value at the JFJ. When air masses originated from Northern Africa, $\alpha_{\text {dry, scat }}$ showed significantly lower values below 1, indicating a domination of coarse mode particles which were transported from the Saharan desert to the JFJ. These Saharan dust events (SDE) are frequently observed (between 10 and 35 SDE per year, see Collaud Coen et al., 2004, for more details). The trajectories in Fig. 2b are color coded by the Ångström exponent of $\omega_{0}$. The mineral dust particles can be differentiated from other coarse mode particles like sea salt by their characteristic spectral behavior of $\omega_{0}$ (fitting Eq. 2 with Eq. 8) in the optical range of $\lambda=450$ to $700 \mathrm{~nm}$. The apparent SDE trajectories show significantly low values (below 0 ) of $\alpha_{\omega_{0}}$, which is mainly caused by a 

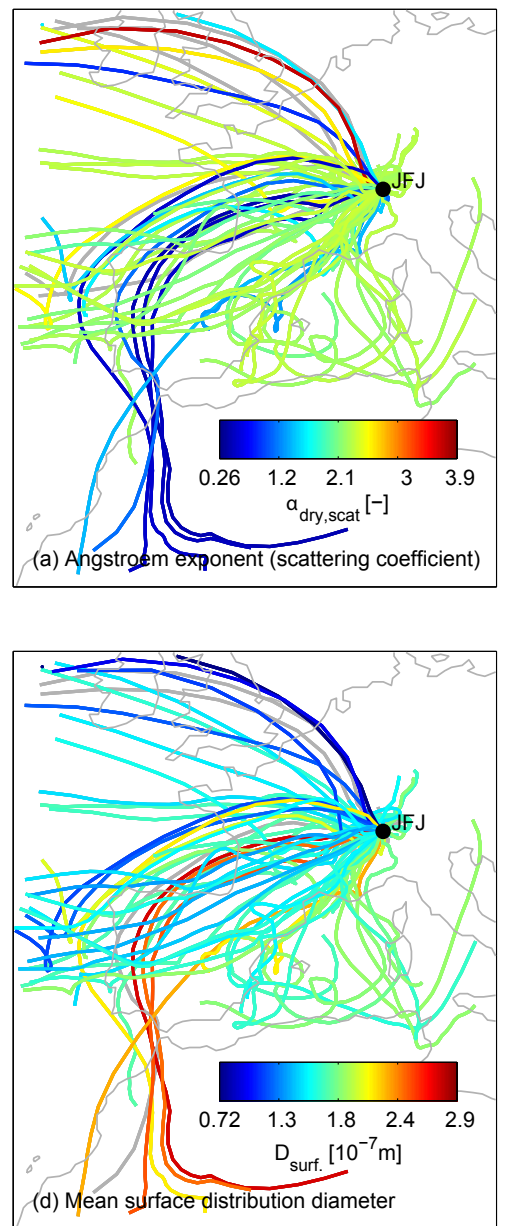
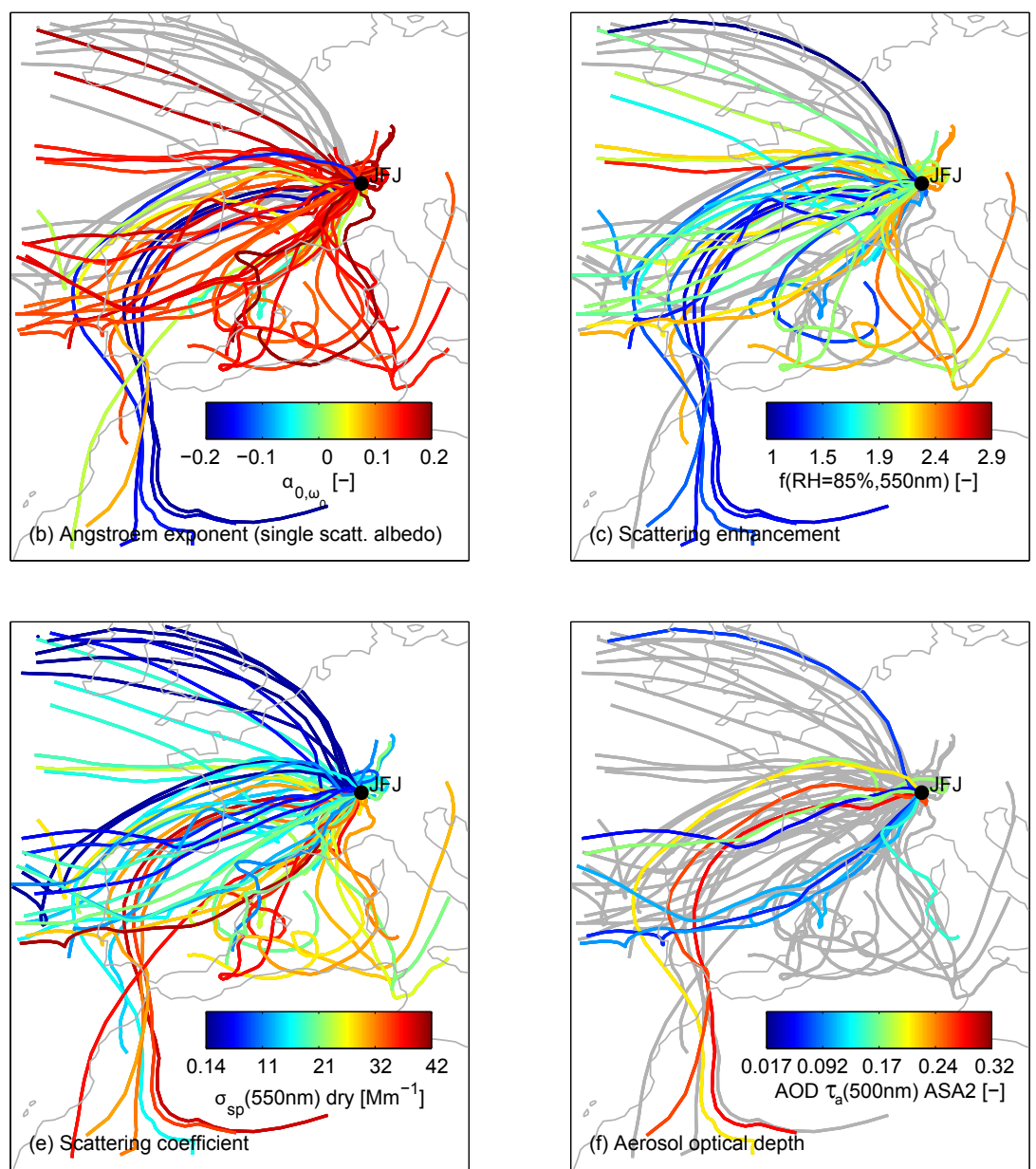

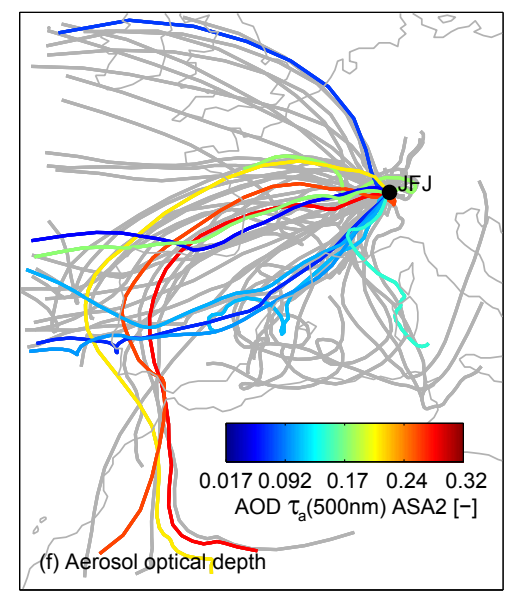

Fig. 2. FLEXTRA air mass trajectories (5-day backward calculations with the Jungfraujoch (JFJ) as endpoint) for the intensive observation period (3-18 July 2010). The color code denotes the specific aerosol parameter measured at the time the air parcel arrived at the site: (a) Ångström exponent of the dry scattering coefficient; (b) Ångström exponent of the dry single scattering albedo (Saharan dust index); (c) scattering enhancement factor at 85\% relative humidity; (d) mean surface diameter; (e) scattering coefficient (dry); (f) aerosol optical depth measured from the Kleine Scheidegg by FUBISS-ASA2. Grey lines are trajectories without data (e.g. in cloudy situations or when measurements are below detection limit or during night-time).

large increase of coarse mode particles with a reddish color (Collaud Coen et al., 2004).

The back trajectories color coded by the aerosol light scattering enhancement $f(\mathrm{RH}=85 \%, 550 \mathrm{~nm})$ at $85 \% \mathrm{RH}$ (Eq. 1) as measured by the WetNeph are displayed in Fig. 2c. The values have been calculated by fitting a two-parameter equation (as e.g. used in Zieger et al., 2011) to the averaged humidograms:

$$
f(\mathrm{RH}, \lambda)=a(1-\mathrm{RH})^{-\gamma} .
$$

The magnitude of $f(\mathrm{RH}=85 \%, 550 \mathrm{~nm})$ is similar to the findings of Fierz-Schmidhauser et al. (2010b). Again, the SDE significantly differs from the other air masses in Fig. 2c with $f(\mathrm{RH}=85 \%, 550 \mathrm{~nm})$ being close to 1 during the SDE due to the low hygroscopic growth of the predominant mineral dust (Sjogren et al., 2008).
The SDE are visible in the aerosol size distribution measurements as well, as depicted in Fig. 2d, where the trajectories are color coded by the mean surface diameter (measured by the SMPS and OPC) which is clearly increased during the $\mathrm{SDE}$. Figures $2 \mathrm{e}$ and $\mathrm{f}$ show the aerosol scattering coefficient measured by the nephelometer at the JFJ and the AOD measured by FUBISS-ASA2 at the KLS. Again, it can be seen that the SDE is also predominant in the extensive aerosol parameters (see Sect. 3.4 below for a more detailed discussion on the SDE).

\subsection{Calculation of optical properties}

The size distributions measured in situ were used to calculate the scattering and absorption coefficients using the Mie code of Bohren and Huffman (2004). For this, the assumptions of spherical particles and an internal mixture were 


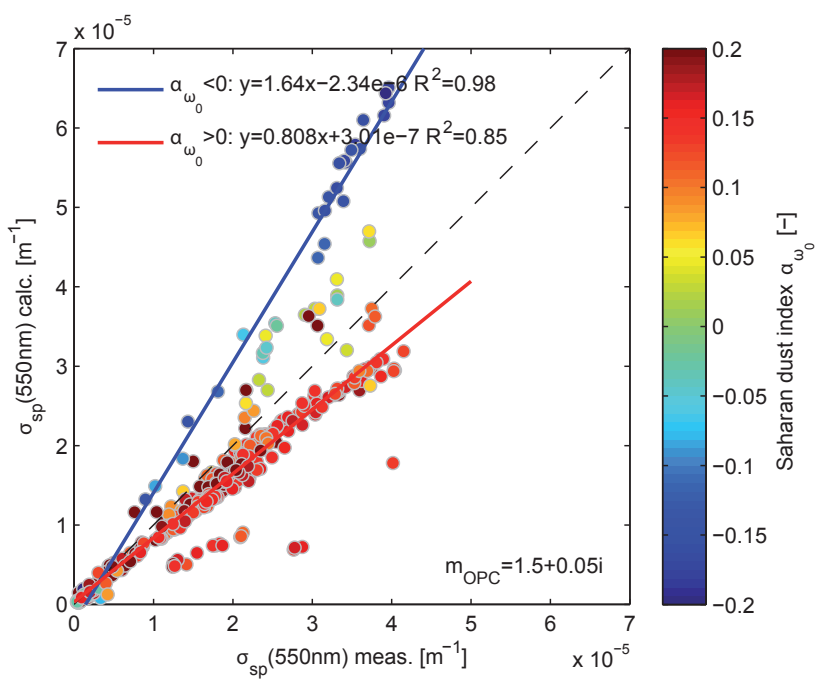

Fig. 3. Calculated vs. measured aerosol light scattering coefficient (dry, at $\lambda=550 \mathrm{~nm}$ and a refractive index for the OPC correction of $m_{\mathrm{OPC}}=1.5+0.05 \mathrm{i}$ as an example). The color code denotes the Ångström exponent of the single scattering albedo $\alpha_{\omega_{0}}$, which is used to identify mineral dust at Jungfraujoch (also called Saharan dust index). Data affected by mineral dust (negative values of $\alpha_{\omega_{0}}$ ) and non-affected data points (positive values of $\alpha_{\omega_{0}}$ ) are fitted separately with a linear least squares regression (solid lines). The black dashed curve represents the 1:1 line.

made. The refractive index is unfortunately unknown due to the lack of chemical characterization during the campaign. For the fine mode, we assume a mean refractive index of $m_{\mathrm{fm}}(550 \mathrm{~nm})=1.52+0.03 \mathrm{i}$ as retrieved at the JFJ during another closure study (also including chemical measurements) in 2008 (Fierz-Schmidhauser et al., 2010b). For the coarse mode, the refractive index of mineral dust $\left(m_{\mathrm{cm}}(550 \mathrm{~nm})=\right.$ $1.53+0.0055 \mathrm{i}$ ) is taken from Hess et al. (1998). A consistent combined size distribution of SMPS (measuring an electrical mobility diameter $<350 \mathrm{~nm}$ ) and OPC (measuring an optical diameter $>350 \mathrm{~nm}$, which also depends on the refractive index of the particle) is difficult to obtain due to an underdetermined problem and the many assumptions that have to be made. The main problem is the influence of the unknown refractive index in the OPC diameter sizing. An example of the calculated versus measured scattering coefficient is seen in Fig. 3. The color code denotes the Ångström exponent of the single scattering albedo $\alpha_{\omega_{0}}$ (also called Saharan dust index, see Sect. 3.4 below), which is used to discriminate the Saharan dust aerosol from the usual aerosol present at the JFJ. The points in Fig. 3 were grouped for values $\alpha_{\omega_{0}}<0$ (Saharan dust influenced) and $\alpha_{\omega_{0}}>0$ (not Saharan dust influenced) and a weighted linear least squares regression was applied for each group. The slopes of the regression lines in Fig. 3 are clearly different for the two different aerosol types predominant at the JFJ. Remaining differences from the individual regression lines are due to the simplified assumptions for the Mie calculations (spherical particles, fixed refractive indices) and the measured aerosol size distribution. Moreover, this example shows that the calculation of the optical properties during the SDE are highly uncertain due to the dominance of non-spherical particles, where Mie theory is not applicable (Nousiainen, 2009). The slope also changes in dependence of the refractive index $m_{\mathrm{OPC}}$ chosen for the OPC correction, while the $R^{2}$ is less affected. In this example, the OPC size distribution was corrected assuming a refractive index of $m_{\mathrm{OPC}}=1.5+0.05 \mathrm{i}$. Nevertheless, this example shows that the optical and microphysical in-situ measurements at the JFJ are in clear correspondence $\left(R^{2}=0.85-0.98\right)$ despite the uncertainties in size and refractive index. The optical closure of the in-situ measurements for the recorded annual datasets is still ongoing work and subject to a separate publication.

\subsection{LIDAR in-situ comparison of the aerosol extinction coefficient}

One main task of this study is the comparison and validation of the in-situ measurements with remote sensing measurements including the humidity effect of the aerosol light scattering. As mentioned above, the initially dry in-situ measurements have to be recalculated to ambient conditions (to ambient RH) using the WetNeph measurements.

The ambient aerosol extinction coefficient is calculated as follows

$\sigma_{\mathrm{ep}}\left(\mathrm{RH}_{\mathrm{amb}}\right)=f\left(\mathrm{RH}_{\mathrm{amb} .}\right) \sigma_{\mathrm{sp}}\left(\mathrm{RH}_{\mathrm{dry}}\right)+\sigma_{\mathrm{ap}}$,

where the scattering enhancement $f\left(\mathrm{RH}_{\mathrm{amb}}\right.$.) is determined by fitting the 3-h averaged humidograms with Eq. (10). This is only done for $\mathrm{RH}_{\mathrm{amb}}<95 \%$, the maximum $\mathrm{RH}$ inside the WetNeph (the uncertainties of the fit are too high at higher $\mathrm{RH}$ as $f(\mathrm{RH}) \rightarrow \infty$ for $\mathrm{RH} \rightarrow 100 \%)$. The absorption coefficient $\sigma_{\mathrm{ap}}$ is interpolated to the specific wavelength using Eq. (8). The absorption enhancement at higher RH can be neglected at the JFJ (Nessler et al., 2005).

The ambient extinction coefficient can be compared directly to the measurement of the LIDAR at the height of the JFJ (3580 $\mathrm{m}$ a.s.1.). As mentioned in Sect. 2.3.1, the LIDAR ratio (LR) has to be assumed and remains the largest uncertainty in the extinction coefficient profiles. Four different values of LR have been selected for the retrieval, all lying in the range of continental, urban and desert aerosol (Ackermann, 1998; Müller et al., 2007). Four example profiles and the corresponding in-situ measurement at the JFJ are shown in Fig. 4. The error of the in-situ measurements is calculated through Gaussian error propagation assuming a $10 \%$ relative error in the DryNeph, WetNeph, and $20 \%$ in the aethalometer measurements (Anderson et al., 1996; Fierz-Schmidhauser et al., 2010a). Figure 4a shows an example where the humidity effect in the in-situ measurements is clearly seen (with $f\left(\mathrm{RH}_{\mathrm{amb}}=84 \%\right)=2.1$ at $355 \mathrm{~nm}$ ). In Fig. $4 \mathrm{~b}$ the humidity effect is less pronounced due to the low 

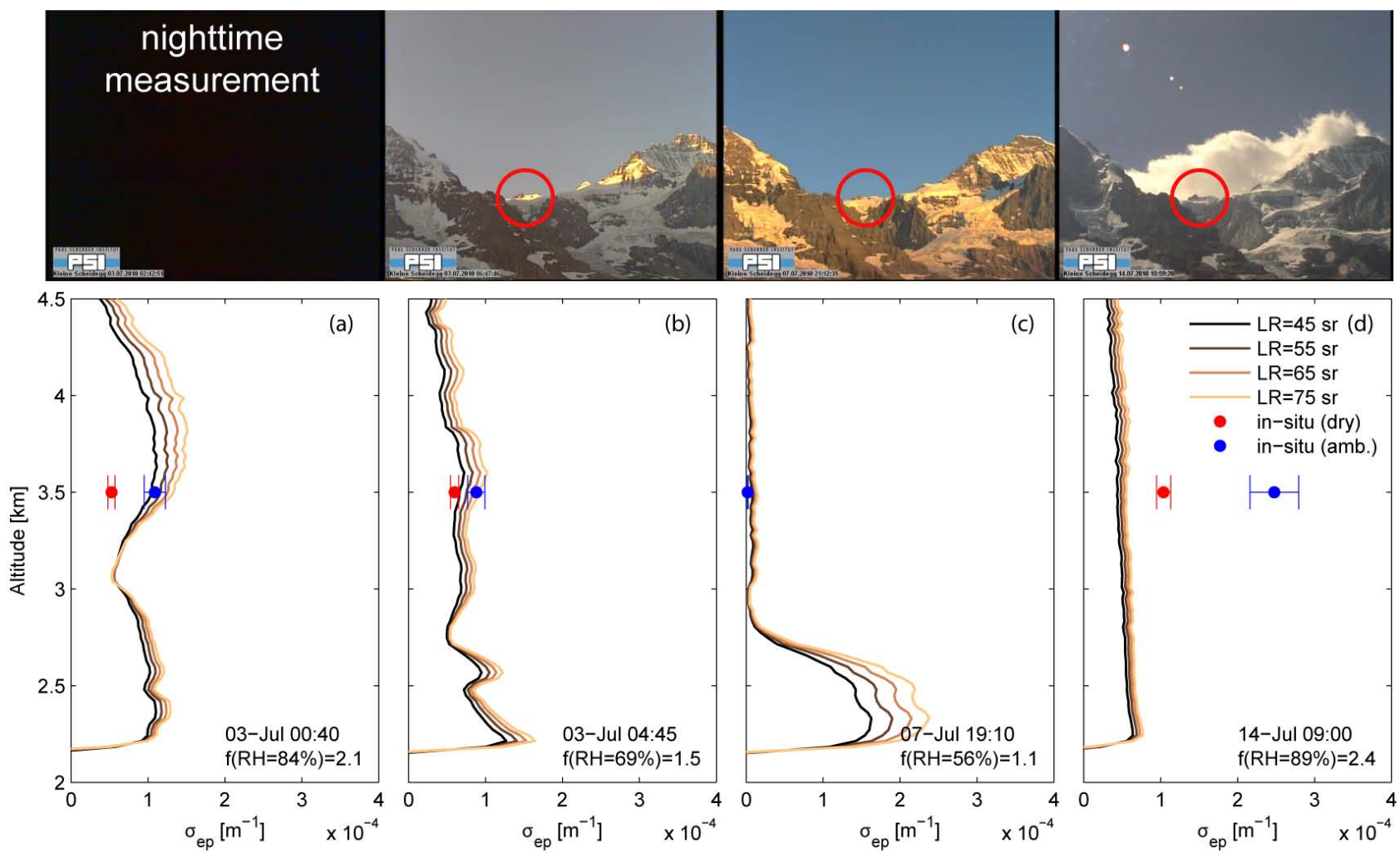

Fig. 4. Example profiles of the aerosol extinction coefficient measured by the LIDAR (solid lines) at different assumed LIDAR ratios (LR) from the Kleine Scheidegg (all at $\lambda=355 \mathrm{~nm}$ ). The corresponding dry and ambient extinction coefficients measured at Jungfraujoch are shown as red and blue bullet points, respectively. The webcam pictures in the upper panel are recorded at the same time (from the Kleine Scheidegg with view towards the Jungfraujoch station, see red circle). In the last example (14 July 2010) the LIDAR was measuring with a zenith angle of $60^{\circ}$, missing the local cloud at the station.

ambient RH. In Fig. 4c the JFJ was in the free troposphere with very low aerosol concentrations, as also measured by the LIDAR. In the fourth example (Fig. 4d) the in-situ extinction coefficient (dry and ambient) clearly exceeds the profile values. This is possibly due to site-specific orographic effects resulting in different air properties sampled by the two methods. While the JFJ station was surrounded by local, patchy clouds with high $\mathrm{RH}_{\mathrm{amb}} \approx 89 \%$ (see camera picture above the profile), the LIDAR was measuring at a zenith angle of $60^{\circ}$ (corresponding to a horizontal distance of about $2.2 \mathrm{~km}$ from the JFJ, see Fig. 1) and therefore sampled possibly a drier air mass compared to the JFJ. These local humid air masses with partially developed clouds were often observed when the air arrived from the south via the Aletsch glacier.

Figure 5a shows the entire time series of the aerosol extinction coefficient measured in situ (dry and at ambient $\mathrm{RH})$ and derived from the LIDAR at the height of the JFJ. The temporal evolution of $\sigma_{\text {ep }}$ is similar for both in-situ and LIDAR and the agreement is good, but differences occur especially during elevated ambient $\mathrm{RH}$. Several reasons can be brought forward to explain the disagreement:
1. Orographic effects causing spatial inhomogeneities

2. Uncertainties in the LIDAR retrieval due to the LR assumed

\section{Losses in the in-situ inlet system}

The losses in the in-situ inlet system probably cause only a minor effect and are assumed to be less than $10-20 \%$ in the optically active particle diameter range of $50 \mathrm{~nm}<D<$ $10 \mu \mathrm{m}$, while the influence of the unknown LR is not as eminent as one would expect (see below). The orographic effects, however, remain the main reason to explain the disagreements found. The JFJ station is located on an exposed saddle at $3580 \mathrm{~m}$ a.s.l., with a large glacial area south of the station (Aletsch glacier). To the north, the mountain range steeply drops by $1500 \mathrm{~m}$ towards the KLS (see Fig. 1). These circumstances probably cause large spatial differences in the wind, temperature, and humidity properties of the air. When the wind at the JFJ originated from the southeast $\left(100-150^{\circ}\right)$ the mean RH was $76.0 \%$, but lower $(73.5 \%)$ when the air originated from northwest $\left(300-360^{\circ}\right)$ during the IOP. This phenomenon is not unusual for this site and is especially observed during foehn wind conditions. For the entire year 

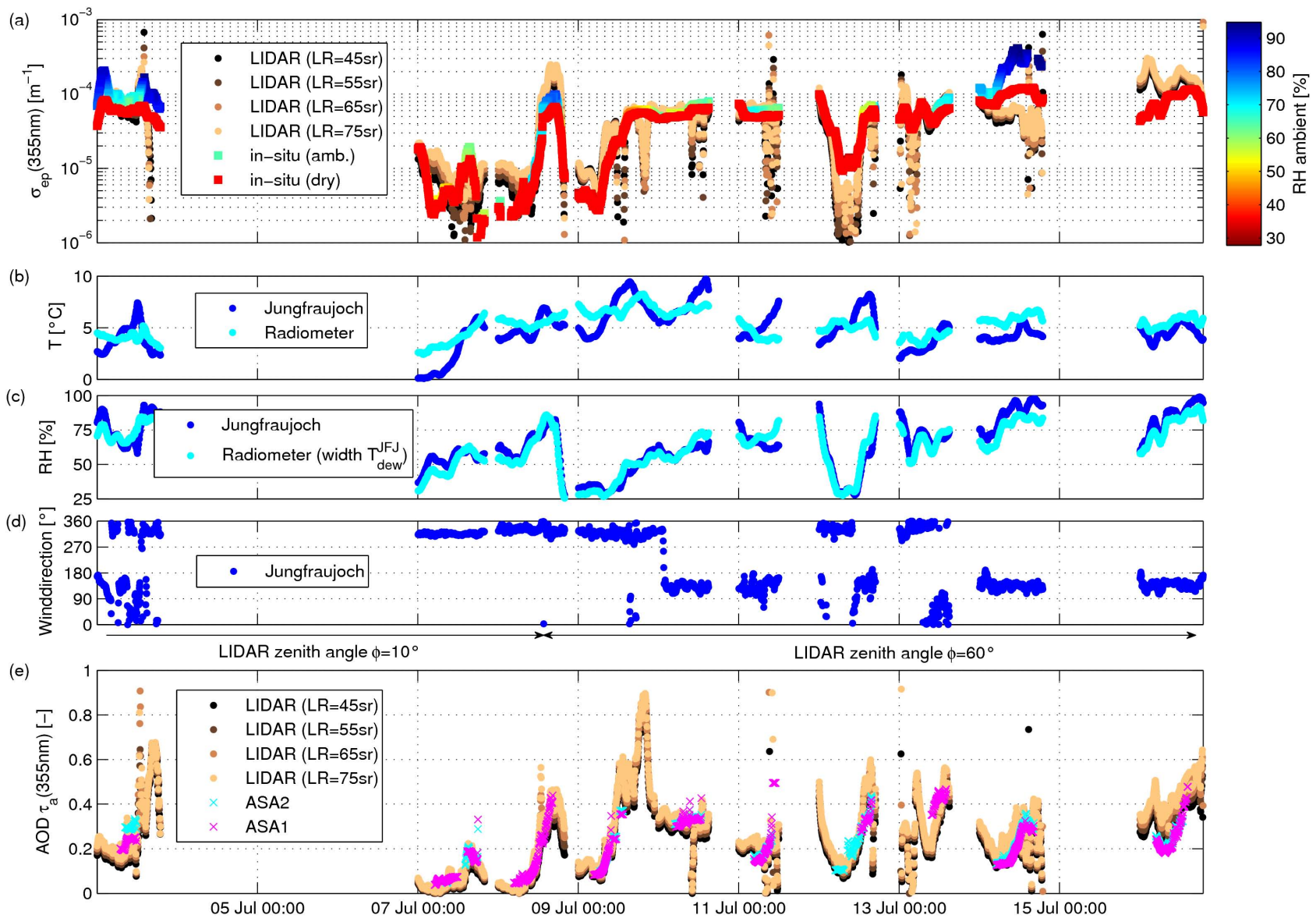

Fig. 5. (a) Time series of the aerosol extinction coefficient (at $\lambda=355 \mathrm{~nm}$ ) measured in-situ at Jungfraujoch (JFJ) (red bullets: dry, colored squares: at ambient RH indicated in the color bar) and by the LIDAR at the altitude of the JFJ (Point C and D in Fig. 1) by assuming different LIDAR ratios (see legend). (b) Ambient temperature at the JFJ (dark blue bullets) and retrieved from radiometer measurements from the Kleine Scheidegg (KLS) here at the height of the JFJ (light blue bullets). (c) Ambient relative humidity at the JFJ (dark blue bullets) and retrieved from radiometer measurements from the KLS at the height of the JFJ (light blue bullets) using the measured dew point temperature of the JFJ and the Magnus formula. (d) Wind direction measured at the JFJ. (e) The aerosol optical depth (AOD) retrieved from the LIDAR at different LIDAR ratios and measured by the Sun photometers FUBISS-ASA1 (magenta crosses) and FUBISS-ASA2 (cyan crosses). The LIDAR was operating with two different zenith angles $\left(10^{\circ}\right.$ and $60^{\circ}$, see arrows).

2010, the differences in RH were similar $(74.9 \%$ and $70.6 \%$ for southeast and northwest, respectively). Clear differences in the (horizontal) wind direction were observed by measurements of the wind profiler at the KLS and an anemometer at the JFJ (Ketterer et al., 2012) during CLACE 2010.

The LIDAR therefore often sampled drier air masses compared to the in-situ measurements at the JFJ due to the measurement geometry chosen (even though the LIDAR was tilted, see Fig. 1, the points being compared had a horizontal distance of $\approx 2-4 \mathrm{~km}$ ). Especially on 14 July 2010 the effect of the elevated RH at the JFJ is obvious (Fig. 5a). On that day a very local and patchy cloud surrounded the JFJ for most of the forenoon while the LIDAR sampled probably much drier air (see web cam picture in Fig. 4d). The wind also originated from south via the glacier (Fig. 5d). Radiometer temperature measurements show higher temperatures above the KLS at the height of the JFJ compared to the station at the JFJ. If the dew point temperature measurements of the JFJ are taken to calculate an RH value above the KLS (assuming the same water content and using the Magnus formula), one can see that the RH is clearly lower above the KLS during this event (see Fig. 5c). This argumentation needs to be treated with caution, since the points being compared are geometrically not the same and the radiometer gives an estimate rather than an exact value of the temperature (as it uses critical input assumptions). Nevertheless, it provides additional hints and clearly supports the findings from the optical interpretation of the webcam pictures.

The LIDAR AOD values (obtained by integrating the $\sigma_{\mathrm{ep}}$ profiles) agree well with the AOD measurements of FUBISSASA1 and ASA2, as demonstrated by Fig. 5e (the AOD of FUBISS-ASA1 and ASA2 has been extrapolated to $355 \mathrm{~nm}$ 

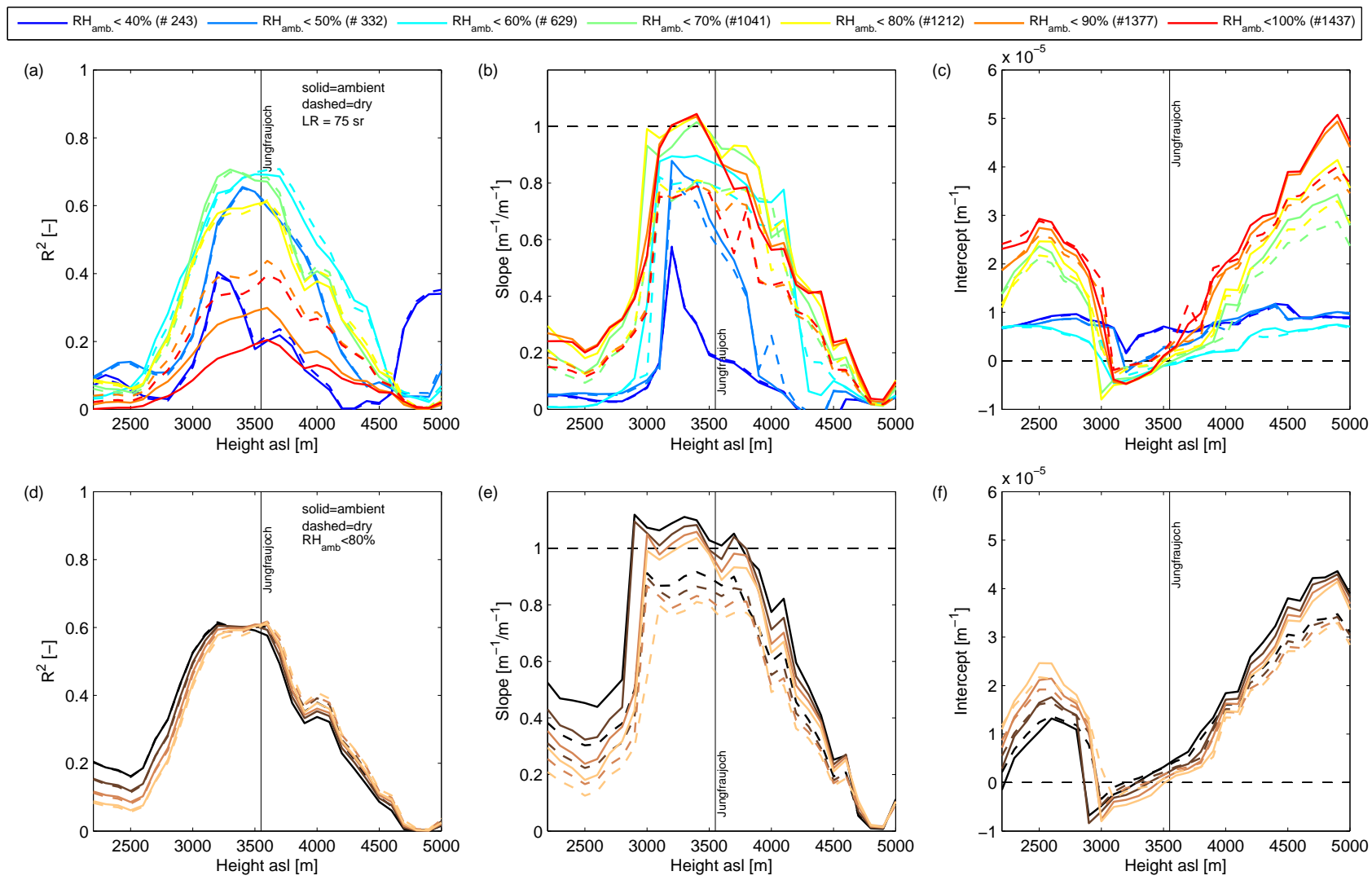

Fig. 6. Comparison of the aerosol extinction coefficient retrieved from the LIDAR measurements and in-situ measurements. The measurements from the Jungfraujoch station (at $3580 \mathrm{~m}$ a.s.1.) were brought to ambient conditions (solid lines) and are compared to the LIDAR measurements at different heights (100 m averages). The corresponding dry in-situ measurements (dashed lines) are shown as well. (a) Correlation coefficient for $\mathrm{LR}=75 \mathrm{sr}$ where the data is categorized by the ambient relative humidity RH (see legend above, number of points is given in brackets), (b and c) Slope and intercept of a weighted linear least squares fit for the same categorization as in panel (a). (d) Correlation coefficient for all measurements and different $\mathrm{LR}$ with $\mathrm{RH}_{\mathrm{amb}}<80 \%$, (e and f) Slope and intercept for the same group of points as in panel (d).

using Eq. (8)). Compared to the AOD of ASA1 the $R^{2}$ ranges between $0.63-0.64$, with a slope between $0.99-1.12$, and an intercept between $0.009-0.017$ for the 4 different LR (obtained by a weighted linear least squares regression). The RMSE of this comparison varied between 0.066 and 0.071 .

The $\sigma_{\mathrm{ep}}$ values of the LIDAR profiles were averaged in 100-m altitude intervals and each mean value was separately compared to the in-situ value measured at the JFJ. The result is seen in Fig. 6, where the squared correlation coefficient $\left(R^{2}\right)$, the slope and the intercept of a weighted linear least squares regression $\left(\sigma_{\mathrm{ap}}^{\mathrm{in}-\mathrm{situ}}=a \cdot \sigma_{\mathrm{ap}}^{\mathrm{LIDAR}}+\sigma_{\mathrm{ap}}^{\prime}\right.$, where $a$ is the slope and $\sigma_{\text {ap }}^{\prime}$ the intercept) are shown versus the altitude above the KLS. Panels a to c of Fig. 6 show the result exemplary for $L R=75 \mathrm{sr}$, while panels $d$ to $f$ show the $R^{2}$, slope and intercept for all points and for all four assumed values of the LR where the ambient RH was below $80 \%$ (excluding the high and possibly cloud affected data points). In all cases, $R^{2}$ shows a maximum of $R^{2} \approx 0.7$ around the height of the JFJ (between 3100-3600 m). This clearly demonstrates a link generally present between in-situ and the LIDAR measurements. The slope of the linear regression is around 1 slightly below the height of the JFJ, while it significantly decreases below and above the altitude of the JFJ. Also the intercept shows a minimum near the JFJ altitude. The clustering of the data concerning the ambient RH (colored lines in Fig. 6a-c) was done to demonstrate the effect of local humid air, which often occurred when the air originated from the Aletsch glacier (southeast wind direction). The agreement improves if high ambient $\mathrm{RH}$ cases are excluded, but worsens again for very low RH, probably due to the low number of points being compared (see legend). The effect of the LR is rather small. The humidity effect on the in-situ data can be seen in the improvement of the slope of the linear regression, where the ambient values show a better slope close to 1 compared to the dry values (dashed lines in Fig. $6 \mathrm{~b}, \mathrm{c}$ ). It has little influence on the value of $R^{2}$ or on the 


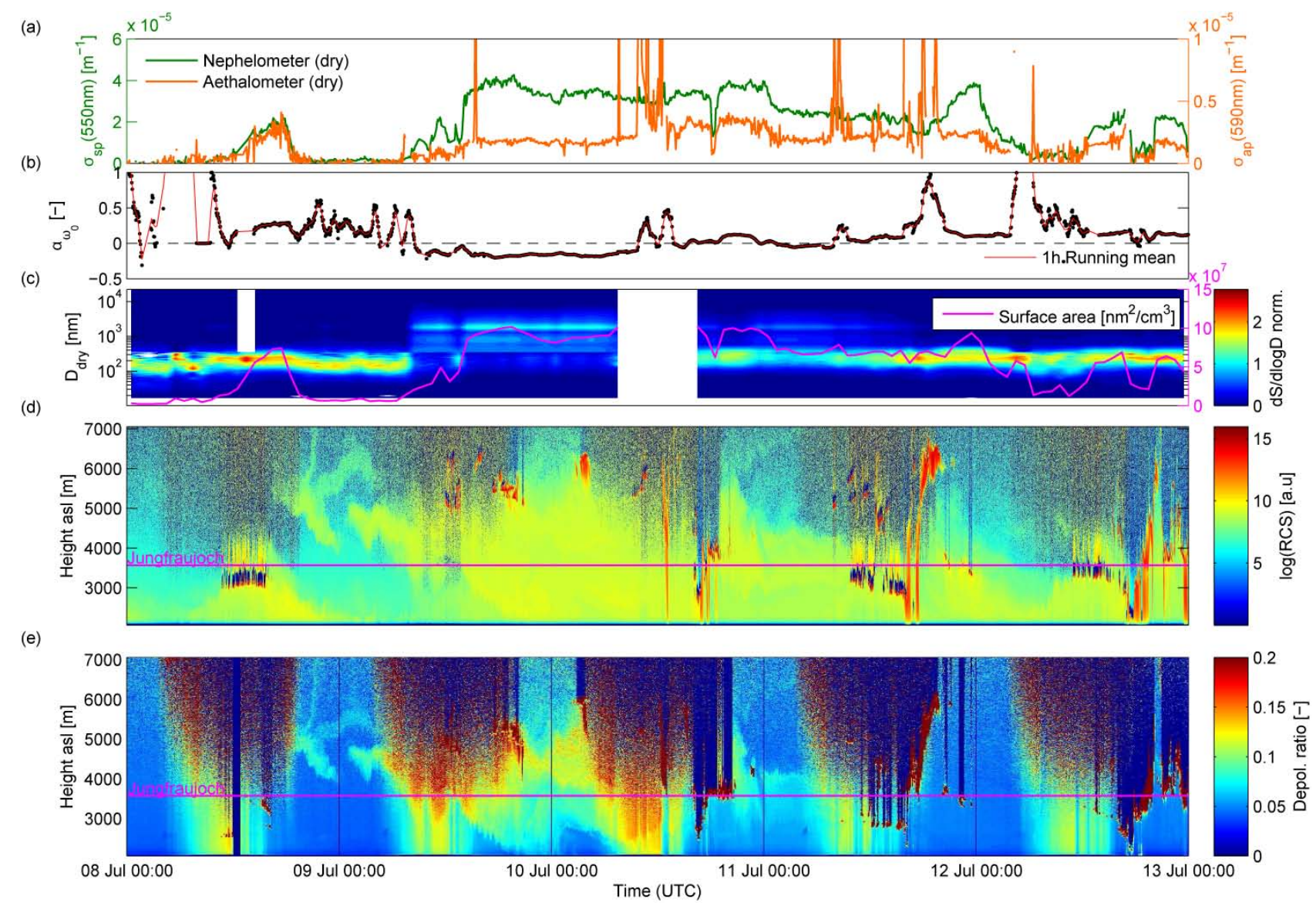

Fig. 7. A strong Saharan dust event was observed by different in-situ and remote sensing instruments. (a-c) are in-situ measurements at the Jungfraujoch station. (a) Dry scattering (green line) and absorption coefficient (orange line); (b) the Ångström exponent of the single scattering albedo (Saharan dust index); (c) normalized surface size distribution measured by the SMPS and OPC (see color code), the mean surface area is shown as well (magenta line); (d) range corrected signal (RCS) of the ceilometer; (e) depolarization ratio measured by the LIDAR. Ceilometer and LIDAR measured from the Kleine Scheidegg. Horizontal magenta line: altitude of the Jungfraujoch at $3580 \mathrm{~m}$ a.s.1.

intercept. Interestingly, the highest $R^{2}$, best slope and minimal intercept are observed about 100-300 m below the JFJ site, which again can probably be attributed to the specific orography and the resulting up and down drafting winds.

To sum up, the two different aerosol extinction measurements - ambient in-situ and by remote sensing technique are in clear correspondence. The differences found are most probably due to the site-specific orography, but minor differences could also be caused by the assumptions within the LIDAR retrieval and possible particle losses in the in-situ inlet system.

\subsection{Saharan dust event during CLACE 2010}

A strong and exceptionally long-lasting mineral dust transport phenomenon was observed during the campaign. As already shown in the back trajectories in Fig. 2, air masses arriving at the JFJ had their origin partly in Northern Africa. All in-situ and remote sensing instruments observed this Saharan dust plume in different manners. Figure 7 shows the time series measured by the in-situ and LIDAR instruments. The dust plume arrived on the afternoon of 8 July 2010 at an altitude of about $5000 \mathrm{~m}$, as can be seen by the ceilometer in Fig. 7d which measures at a wavelength of $1064 \mathrm{~nm}$ and therefore is especially sensitive to coarse mode particles. The plume with a vertical extension of $\approx 1-2 \mathrm{~km}$ slowly loses height and reaches the height of the Jungfraujoch in the morning of 9 July 2010. The vertical extent increases further with time and later the dust particles fill the entire valley above the KLS. The particles are characterized by an increased depolarization ratio up to 0.2 (Eq. 6), as measured by the LIDAR and shown in Fig. 7e, which indicates the presence of non-spherical particles as one would expect for mineral dust. The temporal evolution and shape of the dust plume are very similar in the ceilometer and LIDAR measurements, only a slight time shift is observed due to the different zenith (observation) angles of both instruments (see Fig. 1). The dust plume is detected by the in-situ instruments at the JFJ on 9 July 2010 at around 08:00 a.m. (UTC). The 

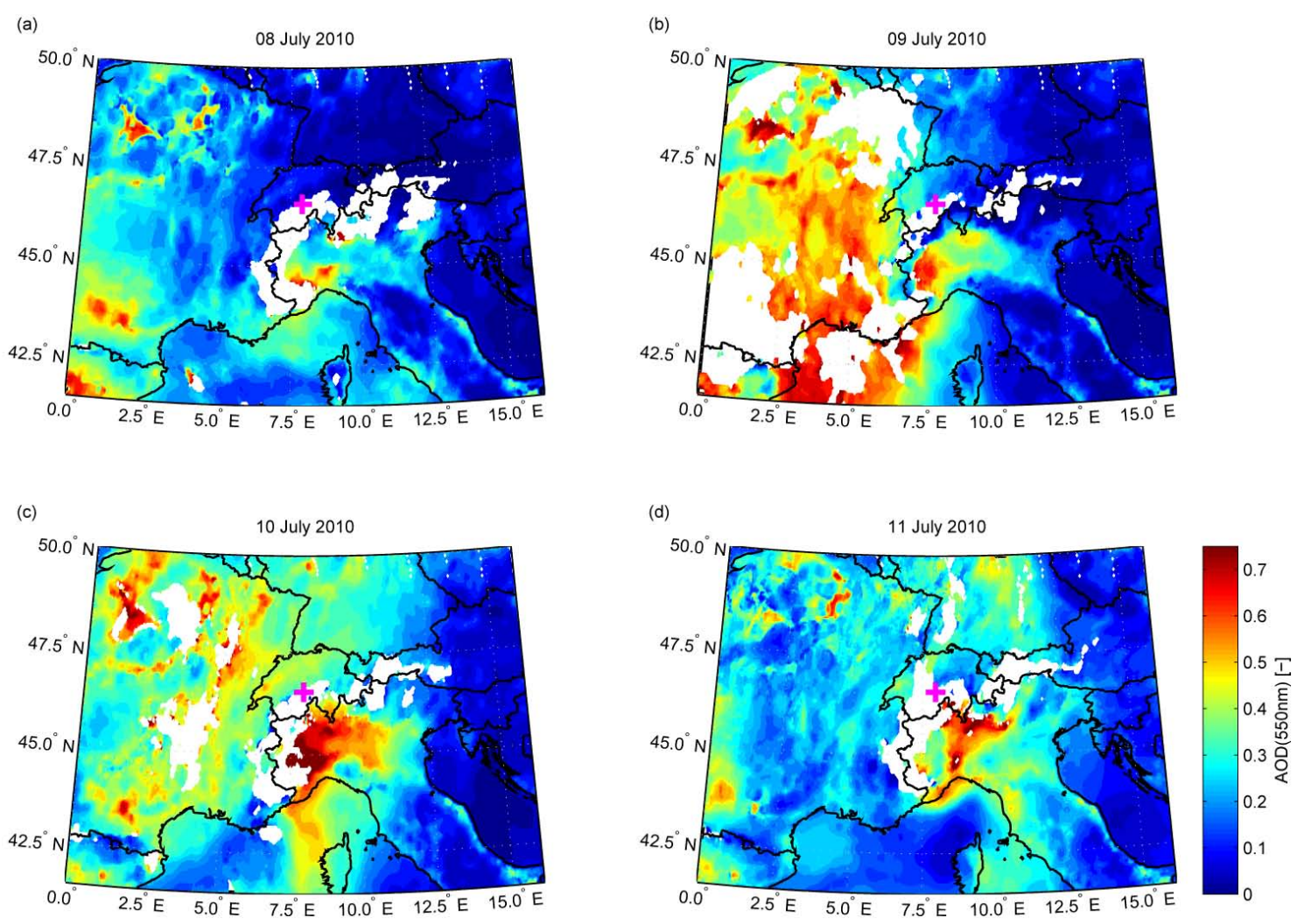

Fig. 8. Maps of daily averaged aerosol optical depth (AOD) retrieved from SEVIRI measurements for the time period of the Saharan dust event (8-11 July 2010) over Switzerland and neighboring countries. White areas are cloud and/or snow covered areas. The magenta cross denotes the location of the JFJ/KLS.

scattering coefficient at $550 \mathrm{~nm}$ and absorption coefficient at $590 \mathrm{~nm}$ increase significantly as the plume arrives (Fig. 7a). The spectral properties clearly change as well, as can be seen by the Ångström exponent of the single scattering albedo $\alpha_{\omega_{0}}$ (Fig. 7b), which turns negative for the first $24 \mathrm{~h}$ pointing towards an enlarged coarse mode fraction and a reddish color of the particles. The normalized surface size distribution together with the surface area concentration is shown in Fig. 7c. The plume period is clearly characterized by an increased coarse mode fraction, which slowly disappears. The presence of coarse mode particles is observed for a longer time in the size distribution measurements (almost $72 \mathrm{~h}$ ) in contrast to $\alpha_{\omega_{0}}$, where the fine mode particles begin to dominate the value of $\alpha_{\omega_{0}}$ already after $24 \mathrm{~h}$. The SDE detection method using $\alpha_{\omega_{0}}$, as proposed by Collaud Coen et al. (2004), could therefore miss periods with an SDE influence due to an enlarged fine mode. Corresponding climatologies of the SDE could be improved by additionally taking the measured size distribution into account. The large extent of this transport phenomena can also be seen in the SEVIRI AOD retrieval (Fig. 8). The dust plume arrived on 8 July 2010 in western France and covered large parts of France and Switzerland on 9 and 10 July 2010. High values of AOD of up to 0.7 (at $550 \mathrm{~nm}$ ) were retrieved during this episode. In addition, the eastbound transport and thinning can clearly be detected in the sequence of AOD maps which are also in good agreement with the trajectories of dust laden air masses in Fig. 2. The dominance of this Saharan dust plume has also a strong effect on the columnar measurements, as will be discussed in the following Sect. 3.5.

\subsection{Columnar observations}

The Sun- and aureole spectrometer systems FUBISS-ASA1 and ASA2, as well as the Precision Filter Radiometers (PFR) can only measure under clear sky conditions, i.e. if no cloud is present between the Sun and the detector of the instrument. The AOD measured at the KLS (by FUBISS-ASA2), at the JFJ (by the PFR), and retrieved from SEVIRI and MODIS are shown in Fig. 9b. Since the AOD of ASA1 and ASA2 agree within a few percent, only AOD data from ASA2 is being used in the following. Valid measurements at the KLS were available mainly during the morning and early afternoon hours. The AOD at the KLS is about a factor 1.2 to 4.5 higher compared to the AOD measured at the JFJ. A higher difference is typically found for times when the PBL does not reach the JFJ (see Fig. 9a, where the average ceilometer profiles are shown for comparison). On 7 July 2010, very 
(a)

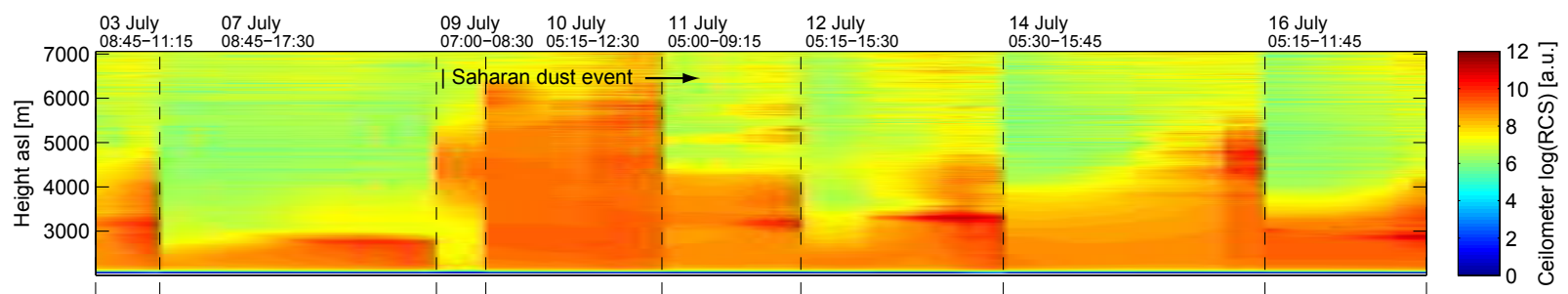

(c)
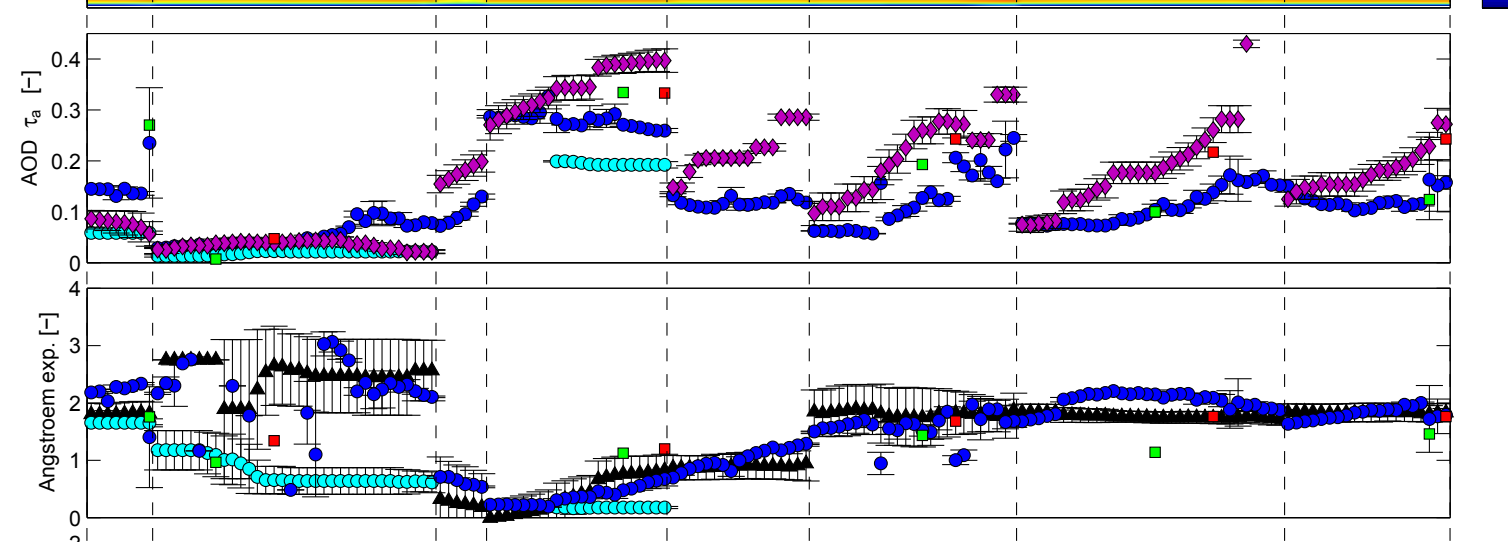

(d)

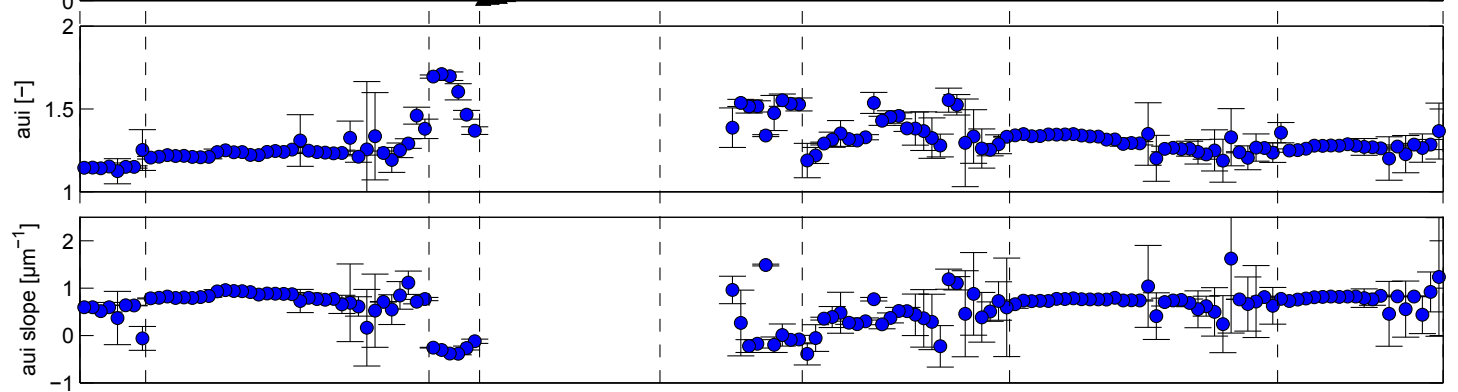

- $\mathrm{KLS}(\mathrm{ASA} 2,500 \mathrm{~nm}) \quad \circ$ JFJ (MeteoSwiss, 500nm)

MODIS aqua $(550 \mathrm{~nm})$

MODIS terra (550nm)

SEVIRI $(550 \mathrm{~nm})$

- JFJ (in-situ, dry)

Fig. 9. Time series of remote sensing measurements (15-min averages during cloud-free daytime periods, error bars denote the standard deviation). (a) Range corrected signal of the ceilometer (Kleine Scheidegg, KLS); (b) aerosol optical depth (AOD) measured by FUBISSASA2 (Kleine Scheidegg, dark blue bullet points), by the Sun photometer of MeteoSwiss (Jungfraujoch, cyan bullet points), and retrieved from MODIS Terra and Aqua (squares), and MSG/SEVIRI (violet diamonds); (c) Ångström exponent measured by the instruments as in (b); (d) aureole index aui (at $\lambda=500 \mathrm{~nm}$ ) of FUBISS-ASA2; (e) spectral slope of aui. No aureole data is available for 10/11 July 2010 (due to signal saturation). Indicated is also the arrival of a Saharan dust plume on 9 July 2010 . The satellite values are averaged over an $0.2^{\circ} \times 0.2^{\circ}$ area.

clean conditions prevailed at the sites with AOD's below 0.1 (at $\lambda=500 \mathrm{~nm}$ ). On 9 and 10 July 2010, the Saharan dust plume arrives at the site and AOD values of the Sun photometers increase significantly to up to 0.3 . The dominance and the large extent in the vertical distribution is well captured by the ceilometer (Fig. 9a). For the following days, the AOD's decrease slowly, while the Saharan dust plume dilutes. A diurnal cycle of the AOD with an increase during the later hours is clearly detected by all instruments for 12 and 14 July 2010, which might be caused by the development of the PBL (e.g. by an increase in RH and aerosol hygroscopic growth and/or lifting of aerosol loaden air). The PFR measurements at the JFJ were not always available during the same times as the KLS measurements due to small and patchy clouds surrounding the JFJ station (see Fig. 4d and Sect. 3.3 above).
The AOD retrieved from MODIS and SEVIRI is added to Fig. 9b and Fig. 9c as well. A meaningful AOD retrieval is only possible for cloud- and snow-free pixels. An average of a $0.2^{\circ} \times 0.2^{\circ}$ square $(\approx 16 \mathrm{~km} \times 16 \mathrm{~km})$ has been chosen for the satellite measurements to guarantee a sufficient number of data points for the time series. This is justified by the low standard deviation of the satellite retrieval for that area. SEVIRI is on board of a geostationary satellite and has a temporal resolution of $15 \mathrm{~min}$, while MODIS is installed on two polar orbiting satellites (Terra and Aqua) which measure twice a day at mid-latitudes. The satellite measurements are of the same magnitude and show a very similar temporal evolution of the AOD as the Sun photometers at the KLS and the JFJ. Especially the increase of the AOD due to the Saharan dust is clearly observed by the satellite measurements. Also the diurnal cycles on 12 and 14 July 2010 are clearly captured by 
SEVIRI and partially by MODIS Terra and Aqua. In general, the AOD's are higher than the ground based Sun photometer measurements, which is reasonable due to the complex terrain. The satellite products generally sense a larger column including lower areas around the JFJ/KLS, e.g. surrounding valleys with enhanced aerosol loads. Another error source could be the fixed aerosol model as an assumption in the SEVIRI retrieval. This is probably not well justified for high loads of dust particles as for example in the case of the SDE.

The Ångström exponent $\alpha_{\mathrm{AOD}}$ (determined by fitting the measured AOD spectra according to Eq. (8)) of the columnar measurements is depicted in Fig. 9c. At the beginning of the IOP, the value of $\alpha_{\mathrm{AOD}}$ lies at around 2, indicating the dominance of the fine mode of the aerosol size distribution. The very low AOD especially on 7 July 2010 caused a high standard deviation (of the $15 \mathrm{~min}$ mean values) and scattering of the data points. On the day of the Saharan dust arrival, $\alpha_{\text {AOD }}$ clearly drops to small values, indicating the presence of coarse mode particles. In the following 3-4 days, the values smoothly increase and recover to the typical background value of 2 again. For comparison, the Ångström exponent of the (dry) aerosol scattering coefficient $\sigma_{\mathrm{sp}}$ measured in situ by the nephelometer at the JFJ is added in Fig. 9c. It shows the same trend and a similar magnitude as the columnar measurements, although it has to be treated with care, since it represents a point measurement at dry conditions, which will differ from the ambient and columnar values. A larger insitu value on 7 July 2010 can also be explained by the fact that $\sigma_{\mathrm{sp}}$ is measured dry and the resulting smaller size will mainly cause a larger value of $\alpha$. However, the dominance of the Saharan dust is observed in the in-situ measurements as well. The Ångström exponent retrieved by MODIS Terra and Aqua also follows a similar trend and magnitude as the Sun photometer measurements, this might be due to coincidence and/or the dominance of the Saharan dust over the Alps. However, one should be aware that the MODIS retrieved aerosol size parameters over land are in general highly uncertain (Levy et al., 2007, 2010) especially over mountains (L. Remer, personal communication, 2011) and should therefore only be interpreted as a qualitative value.

As mentioned above, the two aureole measurements of FUBISS-ASA2 allow the determination of further intensive aerosol parameters. The aui value (Eq. 9) and its spectral behavior (slope) deliver an additional and easily accessible information on the aerosol type, without any difficult measurement geometries and complex inversion schemes which are difficult to perform e.g. during aircraft measurements. The measured aui value and its spectral slope (determined by a linear regression) are shown in Fig. 9d and e. The aui value increases and the spectral slope of the aui value decreases for the periods when the aerosol was dominated by the Saharan dust plume. On 10 and 11 July 2010 (first two hours) the two aureole spectrometer signals were partially saturated due to the largely increased forward scattering and can therefore not be analyzed. Nevertheless, the change in the aui value and its spectral slope is clearly seen on 9 July 2010 when the Saharan dust plume arrived at the site. To demonstrate the additional information content of the aui value, Zieger et al. (2007) performed Mie calculations to model the aui value for different aerosol type examples. It was found that coarse mode dominated aerosol types, like maritime and also mineral dust, showed a negative spectral slope of the aui value and were also characterized by generally larger values of the aui value compared to fine mode dominated aerosol types like continental or urban ones. During the SDE, the aui value increased and the slope turned to a negative one, as predicted.

\section{Conclusions}

The CLACE 2010 campaign provided a unique dataset of aerosol optical and microphysical properties measured by means of various remote sensing and in-situ techniques. During the two-week intensive observation period in summer 2010 different aerosol types, ranging from free tropospheric to long-range transported mineral dust, were sampled at the Jungfraujoch (JFJ, $3580 \mathrm{~m}$ a.s.l.) and the Kleine Scheidegg (KLS, $2060 \mathrm{~m}$ a.s.l.) in the Swiss Alps. A special set-up allowed the positioning of the remote instruments about $1.5 \mathrm{~km}$ below the Jungfraujoch with a direct view towards the station.

The main goal was to check for consistency of the very different measurement techniques but also to assess the spatial variability of aerosol optical properties around the JFJ. Mie calculations showed the consistency within the in-situ measurements at the JFJ despite the large uncertainties due to the assumptions on the refractive index and particle shape. One task was to investigate the agreement between the in-situ measurements of the aerosol extinction coefficient measured at the Jungfraujoch (after transformation to ambient conditions) and retrieved by profile measurements of a LIDAR. In general, a good agreement was found for the LIDAR retrieval at the height of the JFJ compared to direct in-situ measurements (e.g. $R^{2} \approx 0.6$, slope $0.9-1.1$, intercept 0 $0.5 \times 10^{-5} \mathrm{~m}^{-1}$ for $\mathrm{LR}=45-75 \mathrm{sr}$ and ambient $\mathrm{RH}<80 \%$ ). A significant positive effect of including direct measurements of the scattering enhancement by a humidified nephelometer was only seen for certain cases but could not be generally observed for the entire period. This was probably due to strong differences in the local relative humidity, caused by orographic effects which are especially present in mountainous regions. The comparison of the integrated LIDAR profiles with Sun photometer measurements showed a good agreement $\left(R^{2} \approx 0.63-0.64\right.$, slope $0.99-1.12$, intercept $0.009-0.017$ for four different $L R=45-75 \mathrm{sr}$ ).

The spatial and temporal development of a strong Saharan dust plume was observed over several days by all instruments. This enabled us to also include coarse mode dust particles in our study which are only occasionally present at the Jungfraujoch. The dust plume had a clear and strong effect on 
the satellite retrievals, which agreed surprisingly well with the Sun photometer measurements bearing in mind the difficulties of satellite retrievals over mountainous regions. The diurnal cycle of the aerosol optical properties and the dominant effect of the Saharan dust were consistently observed by both techniques. Remaining differences between satellite and local measurements are probably due to the complex mountainous terrain, the averaging effect of the satellite pixels and simplifications in the satellite aerosol retrieval schemes in general. An aureole spectrometer system observed the appearance of the Saharan dust by a change of the instrument specific aureole index and its spectral behavior which is used as a simple aerosol type indicator.

Continuous aerosol in-situ measurements are an important task to improve our knowledge on aerosols, their related processes and their impact on climate in general. For climatologies however, their spatial and vertical distribution should be considered as well, e.g. by installing continuous profiling techniques. A future aerosol closure study could be improved by installing a multi-wavelength Raman LIDAR at the KLS which can directly retrieve profiles of the aerosol extinction coefficient without any assumptions on the LIDAR ratio. In addition, the zenith angle should be larger with an improved positioning of the LIDAR beam closer to the station if not the columnar and rather the in-situ measurements are being compared. A comparison of Sun photometer retrieval of size distribution and other optical parameters with in-situ data (at ambient conditions) is another important task to perform within a future study. For a long-term closure study of the in-situ optical and microphysical measurements, non-spherical calculations like discrete dipole approximation should be used instead of Mie theory to account for the nonspherical mineral dust transported to the JFJ.

Acknowledgements. We thank the International Foundation High Altitude Research Stations Jungfraujoch and Gornergrat (HFSJG) for providing the excellent infrastructure at the Jungfraujoch. Special thanks go to the custodians Felix and Susanne Seiler as well as Joan and Martin Fischer, for their help during the campaign. We also acknowledge the Jungfraubahnen for providing the infrastructure at the Kleine Scheidegg. We thank Holger Wille and Steffen Frey (Jenoptics) for their support and for lending the ceilometer. NILU is acknowledged for providing the FLEXTRA trajectories. We also acknowledge the MODIS mission scientists and associated NASA personnel for the production of the aerosol data (MOD08D3 and MYD08D3) used in this research effort. This work was financially supported by the EC-projects European Supersites for Atmospheric Aerosol Research (EUSAAR, contract 026140) and Global Earth Observation and Monitoring (GEOMON, contract 026140), as well as by the European Space Agency's Climate Change Initiative (aerosol_cci) and by $\mathrm{Me}-$ teoSwiss within the Global Atmosphere Watch programme (GAW) of the World Meteorological Organization (WMO).

Edited by: E. Gerasopoulos

\section{References}

Ackermann, J.: The extinction-to-backscatter ratio of tropospheric aerosol: A numerical study, J. Atmos. Oceanic Technol., 15, 1043-1050, 1998.

Anderson, T. and Ogren, J.: Determining aerosol radiative properties using the TSI 3563 integrating nephelometer, Aerosol Sci. Technol., 29, 57-69, 1998.

Anderson, T., Covert, D., Marshall, S., Laucks, M., Charlson, R., Waggoner, A., Ogren, J., Caldow, R., Holm, R., Quant, F., Sem, G., Wiedensohler, A., Ahlquist, N., and Bates, T.: Performance characteristics of a high-sensitivity, three-wavelength, total scatter/backscatter nephelometer, J. Atmos. Ocean. Technol., 13, 967-986, 1996.

Ansmann, A., Petzold, A., Kandler, K., Tegen, I., Wendisch, M., Müller, D., Weinzierl, B., Müller, T., and Heintzenberg, J.: Saharan Mineral Dust Experiments SAMUM-1 and SAMUM-2: what have we learned?, Tellus B, 63, 403-429, doi:10.1111/j.16000889.2011.00555.x, 2011.

Asseng, H., Ruhtz, T., and Fischer, J.: Sun and aureole spectrometer for airborne measurements to derive aerosol optical properties, Appl. Opt., 43, 2146-2155, doi:10.1364/AO.43.002146, 2004.

Baltensperger, U., Gäggeler, H., Jost, D., Lugauer, M., Schwikowski, M., Weingartner, E., and Seibert, P.: Aerosol climatology at the high-alpine site Jungfraujoch, Switzerland, J. Geophys. Res., 102, 19707-19715, doi:10.1029/97JD00928, 1997.

Bohren, C. and Huffman, D.: Absorption and Scattering of Light by Small Particles, Wiley-VCH, 2004.

Bucholtz, A.: Rayleigh-scattering calculations for the terrestrial atmosphere, Appl. Opt., 34, 2765-2773, 1995.

Bukowiecki, N., Zieger, P., Weingartner, E., Jurányi, Z., Gysel, M., Neininger, B., Schneider, B., Hueglin, C., Ulrich, A., Wichser, A., Henne, S., Brunner, D., Kaegi, R., Schwikowski, M., Tobler, L., Wienhold, F. G., Engel, I., Buchmann, B., Peter, T., and Baltensperger, U.: Ground-based and airborne in-situ measurements of the Eyjafjallajökull volcanic aerosol plume in Switzerland in spring 2010, Atmos. Chem. Phys., 11, 10011-10030, doi:10.5194/acp-11-10011-2011, 2011.

Chin, M., Kahn, R., and Schwartz, S., eds.: Atmospheric Aerosol Properties and Climate Impacts, A Report by the U.S. Climate Change Science Program and the Subcommittee on Global Change Research, National Aeronautics and Space Administration, Washington DC, USA, 2009.

Collaud Coen, M., Weingartner, E., Schaub, D., Hueglin, C., Corrigan, C., Henning, S., Schwikowski, M., and Baltensperger, U.: Saharan dust events at the Jungfraujoch: Detection by wavelength dependence of the single scattering albedo and first climatology analysis, Atmos. Chem. Phys., 4, 2465-2480, doi:10.5194/acp-4-2465-2004, 2004.

Collaud Coen, M., Weingartner, E., Nyeki, S., Cozic, J., Henning, S., Verheggen, B., Gehrig, R., and Baltensperger, U.: Long-term trend analysis of aerosol variables at the highalpine site Jungfraujoch, J. Geophys. Res., 112, D13213, doi:10.1029/2006JD007995, 2007.

Collaud Coen, M., Weingartner, E., Apituley, A., Ceburnis, D., Fierz-Schmidhauser, R., Flentje, H., Henzing, J., Jennings, S., Moerman, M., Petzold, A., Schmid, O., and Baltensperger, U.: Minimizing light absorption measurement artifacts of the Aethalometer: Evaluation of five correction algorithms, Atmos. 
Meas. Tech., 3, 457-474, doi:10.5194/amt-3-457-2010, 2010.

Collaud Coen, M., Weingartner, E., Furger, M., Nyeki, S., Prévôt, A. S. H., Steinbacher, M., and Baltensperger, U.: Aerosol climatology and planetary boundary influence at the Jungfraujoch analyzed by synoptic weather types, Atmos. Chem. Phys., 11, 5931-5944, doi:10.5194/acp-11-5931-2011, 2011.

Crewell, S. and Löhnert, U.: Accuracy of boundary layer temperature profiles retrieved with multifrequency multiangle microwave radiometry, IEEE T. Geosci. Remote., 45, 2195-2201, 2007.

Emili, E., Popp, C., Petitta, M., Riffler, M., Wunderle, S., and Zebisch, M.: PM10 remote sensing from geostationary SEVIRI and polar-orbiting MODIS sensors over the complex terrain of the European Alpine region, Remote Sens. Environ., 114, 24852499, doi:10.1016/j.rse.2010.05.024, 2010.

Emili, E., Lyapustin, A., Wang, Y., Popp, C., Korkin, S., Zebisch, M., Wunderle, S., and Petitta, M.: High spatial resolution aerosol retrieval with MAIAC: Application to mountain regions, J. Geophys. Res., 116, D23211, doi:10.1029/2011JD016297, 2011.

Fiebig, M., Petzold, A., Wandinger, U., Wendisch, M., Kiemle, C., Stifter, A., Ebert, M., Rother, T., and Leiterer, U.: Optical closure for an aerosol column: Method, accuracy, and inferable properties applied to a biomass-burning aerosol and its radiative forcing, J. Geophys. Res., 107, 8130, doi:10.1029/2000JD000192, 2002.

Fierz-Schmidhauser, R., Zieger, P., Wehrle, G., Jefferson, A., Ogren, J., Baltensperger, U., and Weingartner, E.: Measurement of relative humidity dependent light scattering of aerosols, Atmos. Meas. Tech., 3, 39-50, doi:10.5194/amt-3-39-2010, 2010a.

Fierz-Schmidhauser, R., Zieger, P., Gysel, M., Kammermann, L., DeCarlo, P., Baltensperger, U., and Weingartner, E.: Measured and predicted aerosol light scattering enhancement factors at the high alpine site Jungfraujoch, Atmos. Chem. Phys., 10, 23192333, doi:10.5194/acp-10-2319-2010, 2010 b.

Ghan, S. and Schwartz, S.: Aerosol properties and processes, Bull. Amer. Meteor. Soc., 88, 1059-1083, 2007.

Gobbi, G. P., Barnaba, F., Van Dingenen, R., Putaud, J. P., Mircea, M., and Facchini, M. C.: Lidar and in situ observations of continental and Saharan aerosol: closure analysis of particles optical and physical properties, Atmos. Chem. Phys., 3, 2161-2172, doi:10.5194/acp-3-2161-2003, 2003.

Hammer, E., Bukowiecki, N., Gysel, M., Hoyle, C., Jurányi, Z., Leuenberger, M., Baltensperger, U., and Weingartner, E.: Interpretation of the activation behaviour of cloud condensation nuclei in liquid-phase clouds at the Jungfraujoch using a comparison of in-situ measurements and box modelling data, Atmos. Chem. Phys. Discuss. in preparation, 2012.

Hess, M., Koepke, P., and Schult, I.: Optical properties of aerosols and clouds: The software package OPAC, Bull. Amer. Meteor. Soc., 79, 831-844, 1998.

Hoff, R., Guise-Bagley, L., Staebler, R., Wiebe, H., Brook, J., Georgi, B., and Düsterdiek, T.: Lidar, nephelometer, and in situ aerosol experiments in southern Ontario, J. Geophys. Res., 101, 19199-19209, 1996.

Hoffmann, A., Osterloh, L., Stone, R., Lampert, A., Ritter, C., Stock, M., Tunved, P. , Hennig, T., Böckmann, C., Li, S., Eleftheriadis, K., Maturillia, M., Orgis, T., Herber, A., Neuber, R., and Dethloff, K.: Remote sensing and in-situ measurements of tropospheric aerosol, a PAMARCMiP case study, Atmos. Environ., 52, 56-66, doi:10.1016/j.atmosenv.2011.11.027, 2012.
Holben, B., Eck, T., Slutsker, I., Tanre, D., Buis, J., Setzer, A., Vermote, E., Reagan, J., Kaufman, Y., Nakajia, T., Lavenu, F., Jankowiak, I., and Smirnov, A.: AERONET - A federated instrument network and data archive for aerosol characterization, Remote Sens. Environ., 66, 1-6, 1998.

Kaufman, Y., Tanré, D., Remer, L., Vermote, E., Chu, A., and Holben, B.: Operational remote sensing of tropospheric aerosol over land from EOS moderate resolution imaging spectroradiometer, J. Geophys. Res., 102, 17-51, 1997.

Kaufman, Y., Tanré, D., and Boucher, O.: A satellite view of aerosols in the climate system, Nature, 419, 215-223, 2002.

Ketterer, C., Zieger, P., Bukowiecki, N., Weingartner, E., Collaud Coen, M., Maier, O., and Ruffieux, D.: Investigation of the planetary boundary layer using remote sensing and in-situ measurements at the Kleine Scheidegg and Jungfraujoch, Atmos. Meas. Tech. Discuss., in preparation, 2012.

King, M. and Byrne, D.: A method for inferring total ozone content from the spectral vaiation of total optical depth obtained with a solar radiometer, J. Atmos. Sci., 33, 2242-2251, 1978.

Kovalev, V. and Eichinger, W.: Elastic Lidar, Wiley Online Library, John Wiley \& Sons, Inc., Hoboken, NJ, USA, doi:10.1002/0471643173.ch5, Chapter 5, 143-183, 2004.

Levy, R., Remer, L., Mattoo, S., Vermote, E., and Kaufman, Y.: Second-generation operational algorithm: Retrieval of aerosol properties over land from inversion of Moderate Resolution Imaging Spectroradiometer spectral reflectance, J. Geophys. Res., 112, D13211, doi:10.1029/2006JD007811, 2007.

Levy, R. C., Remer, L. A., Kleidman, R. G., Mattoo, S., Ichoku, C., Kahn, R., and Eck, T. F.: Global evaluation of the Collection 5 MODIS dark-target aerosol products over land, Atmos. Chem. Phys., 10, 10399-10420, doi:10.5194/acp-10-10399-2010, 2010.

Löhnert, U. and Maier, O.: Operational profiling of temperature using ground-based microwave radiometry at Payerne: prospects and challenges, Atmos. Meas. Tech., 5, 1121-1134, doi:10.5194/amt-5-1121-2012, 2012.

Müller, D., Ansmann, A., Mattis, I., Tesche, M., Wandinger, U., Althausen, D., and Pisani, G.: Aerosol-type-dependent lidar ratios observed with Raman lidar, J. Geophys. Res., 112, D16202, doi:10.1029/2006JD008292, 2007.

Nessler, R., Weingartner, E., and Baltensperger, U.: Effect of humidity on aerosol light absorption and its implications for extinction and the single scattering albedo illustrated for a site in the lower free troposphere, J. Aerosol Sci., 36, 958-972, doi:10.1016/j.jaerosci.2004.11.012, 2005.

Nousiainen, T.: Optical modeling of mineral dust particles: A review, J. Quant. Spec. Rad. Trans., 110, 1261-1279, 2009.

Nyeki, S., Baltensperger, U., Colbeck, I., Jost, D. T., Weingartner, E., and Gäggeler, H. W.: The Jungfraujoch high-Alpine research station ( $3454 \mathrm{~m}$ ) as a background clean continental site for the measurement of aerosol parameters, J. Geophys. Res., 103, 6097-6107, doi:10.1029/97JD03123, 1998.

Ogren, J.: A systematic approach to in situ observations of aerosol properties, Aerosol forcing of climate, Dahlem Konferenzen 1994, 1995.

Pahlow, M., Feingold, G., Jefferson, A., Andrews, E., Ogren, J., Wang, J., Lee, Y., Ferrare, R., and Turner, D.: Comparison between lidar and nephelometer measurements of aerosol hygroscopicity at the Southern Great Plains Atmospheric Radiation Measurement site, J. Geophys. Res., 111, D05S15, 
doi:10.1029/2004JD005646, 2006.

Penner, J., Charlson, R., Schwartz, S., Hales, J., Laulainen, N., Travis, L., Leifer, R., Novakov, T., Ogren, J., and Radke, L.: Quantifying and minimizing uncertainty of climate forcing by anthropogenic aerosols, B. Am. Meteor. Soc., 75, 375-400, 1994.

Popp, C., Hauser, A., Foppa, N., and Wunderle, S.: Remote sensing of aerosol optical depth over central Europe from MSG-SEVIRI data and accuracy assessment with ground-based AERONET measurements, J. Geophys. Res., 112, D24S11, doi:10.1029/2007JD008423, 2007.

Popp, C., Riffler, M., Emili, E., Petitta, M., and Wunderle, S.: Evaluation of operationally derived aerosol optical depth from MSGSEVIRI over Central Europe, Geophys. Res. Abstr., 11, p. 9362, 2009

Russell, P. and Heintzenberg, J.: An overview of the ACE-2 clear sky column closure experiment (CLEARCOLUMN), Tellus B, 52, 463-483, 2000.

Schmid, B. and Wehrli, C.: Comparison of Sun photometer calibration by use of the Langley technique and the standard lamp, Appl. Opt., 34, 4500-4512, 1995.

Schmid, B., Hegg, D., Wang, J., Bates, D., Redemann, J., Russell, P., Livingston, J., Jonsson, H., Welton, E., Seinfeld, J., Flagan, R., Covert, D., Dubovik, O., and Jefferson, A.: Column closure studies of lower tropospheric aerosol and water vapor during ACE-Asia using airborne Sun photometer and airborne in situ and ship-based lidar measurements, J. Geophys. Res., 108, 8656, doi:10.1029/2002JD003361, 2003.

Schmid, B., Ferrare, R., Flynn, C., Elleman, R., Covert, D., Strawa, A., Welton, E., Turner, D., Jonsson, H., Redemann, J., Eilers, J., Ricci, K., Hallar, A., Clayton, M., Michalsky, J., Smirnov, A., Holben, B., and J., B.: How well do state-ofthe-art techniques measuring the vertical profile of tropospheric aerosol extinction compare?, J. Geophys. Res., 111, D05S07, doi:10.1029/2005JD005837, 2006.

Schwikowski, M., Seibert, P., Baltensperger, U., and Gäggeler, H.: A study of an outstanding Saharan dust event at the high-alpine site Jungfraujoch, Switzerland, Atmos. Environ., 29, 1829-1842, 1995.

She, C.: Spectral structure of laser light scattering revisited: bandwidths of nonresonant scattering lidars, Appl. Opt., 40, 48754884, 2001.

Sjogren, S., Gysel, M., Weingartner, E., Alfarra, M., Duplissy, J., Cozic, J., Crosier, J., Coe, H., and Baltensperger, U.: Hygroscopicity of the submicrometer aerosol at the high-alpine site Jungfraujoch, $3580 \mathrm{~m}$ a.s.l., Switzerland, Atmos. Chem. Phys., 8, 5715-5729, doi:10.5194/acp-8-5715-2008, 2008.

Spiegel, J., Zieger, P., Bukowiecki, N., Hammer, E., Weingartner, E., and Eugster, W.: Evaluating the capabilities and uncertainties of droplet measurements for the fog droplet spectrometer (FM-100), Atmos. Meas. Tech. Discuss., 5, 3333-3393, doi:10.5194/amtd-5-3333-2012, 2012.

Stohl, A. and Seibert, P.: Accuracy of trajectories as determined from the conservation of meteorological tracers, Q. J. Roy. Meteo. Soc., 124, 1465-1484, 1998.

Stohl, A., Wotawa, G., Seibert, P., and Kromp-Kolb, H.: Interpolation errors in wind fields as a function of spatial and temporal resolution and their impact on different types of kinematic trajectories, J. Appl. Meteorol., 34, 2149-2165, 1995.
Tanaka, M., Nakajima, T., and Shiobara, M.: Calibration of a sunphotometer by simultaneous measurements of direct-solar and circumsolar radiations, Appl. Opt., 25, 1170-1176, 1986.

Trenberth, K., Fasullo, J., and Kiehl, J.: Earth's global energy budget, Bull. Amer. Meteor. Soc., 90, 311-323, 2009.

Wehrli, C.: Calibrations of filter radiometers for determination of atmospheric optical depth, Metrologia, 37, 419, doi:10.1088/00261394/37/5/16, 2000

Weingartner, E., Nyeki, S., and Baltensperger, U.: Seasonal and diurnal variation of aerosol size distributions $(10<\mathrm{D}<750 \mathrm{~nm})$ at a high-alpine site (Jungfraujoch $3580 \mathrm{~m}$ asl), J. Geophys. Res., 104, 26 809-26 820, doi:10.1029/1999JD900170, 1999.

Weingartner, E., Saathoff, H., Schnaiter, M., Streit, N., Bitnar, B., and Baltensperger, U.: Absorption of light by soot particles: Determination of the absorption coefficient by means of Aethalometers, J. Aerosol Sci., 34, 1445-1465, 2003.

Weitkamp, C.: Lidar: Range-Resolved Optical Remote Sensing of the Atmosphere, 102, Springer, NY, USA, 2005.

Wex, H., Neusüß, C., Wendisch, M., Stratmann, F., Koziar, C., Keil, A., Wiedensohler, A., and Ebert, M.: Particle scattering, backscattering, and absorption coefficients: An in situ closure and sensitivity study, J. Geophys. Res., 107, 8122, doi:10.1029/2000JD000234, 2002.

Wiedensohler, A., Birmili, W., Nowak, A., Sonntag, A., Weinhold, K., Merkel, M., Wehner, B., Tuch, T., Pfeifer, S., Fiebig, M., Fjäraa, A. M., Asmi, E., Sellegri, K., Depuy, R., Venzac, H., Villani, P., Laj, P., Aalto, P., Ogren, J. A., Swietlicki, E., Williams, P., Roldin, P., Quincey, P., Hüglin, C., Fierz-Schmidhauser, R., Gysel, M., Weingartner, E., Riccobono, F., Santos, S., Grüning, C., Faloon, K., Beddows, D., Harrison, R., Monahan, C., Jennings, S. G., O’Dowd, C. D., Marinoni, A., Horn, H.-G., Keck, L., Jiang, J., Scheckman, J., McMurry, P. H., Deng, Z., Zhao, C. S., Moerman, M., Henzing, B., de Leeuw, G., Löschau, G., and Bastian, S.: Mobility particle size spectrometers: harmonization of technical standards and data structure to facilitate high quality long-term observations of atmospheric particle number size distributions, Atmos. Meas. Tech., 5, 657-685, doi:10.5194/amt5-657-2012, 2012.

WMO/GAW: Aerosol Measurement Procedures Guidelines and Recommendations, Report No. 153, World Meteorological Organization, Geneva, Switzerland, 2003.

Zieger, P., Ruhtz, T., Preusker, R., and Fischer, J.: Dualaureole and sun spectrometer system for airborne measurements of aerosol optical properties, Appl. Opt., 46, 8542-8552, doi:10.1364/AO.46.008542, 2007.

Zieger, P., Weingartner, E., Henzing, J., Moerman, M., de Leeuw, G., Mikkilä, J., Ehn, M., Petäjä, T., Clémer, K., van Roozendael, M., Yilmaz, S., Frieß, U., Irie, H., Wagner, T., Shaiganfar, R., Beirle, S., Apituley, A., Wilson, K., and Baltensperger, U.: Comparison of ambient aerosol extinction coefficients obtained from in-situ, MAX-DOAS and LIDAR measurements at Cabauw, Atmos. Chem. Phys., 11, 2603-2624, doi:10.5194/acp11-2603-2011, 2011. 